June 1999 • NREL/EL-550-25976

\title{
Business Opportunity Prospectus for Utilities in Solar Water Heating
}

Energy Alliance Group

With the support of the Solar Energy Industries Association (SEIA), the US Department of Energy (DOE), and the National Renewable Energy Laboratory (NREL) pursuant to Task Order 78, Contract Number HI-2-12006-0.

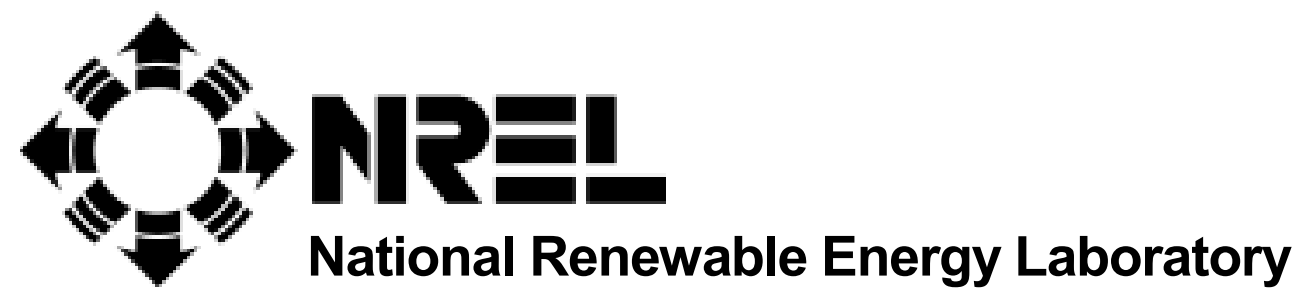

1617 Cole Boulevard Golden, Colorado 80401-3393

NREL is a U.S. Department of Energy Laboratory Operated by Midwest Research Institute $\bullet$ Battelle $\bullet$ Bechtel 


\section{NOTICE}

This report was prepared as an account of work sponsored by an agency of the United States government. Neither the United States government nor any agency thereof, nor any of their employees, makes any warranty, express or implied, or assumes any legal liability or responsibility for the accuracy, completeness, or usefulness of any information, apparatus, product, or process disclosed, or represents that its use would not infringe privately owned rights. Reference herein to any specific commercial product, process, or service by trade name, trademark, manufacturer, or otherwise does not necessarily constitute or imply its endorsement, recommendation, or favoring by the United States government or any agency thereof. The views and opinions of authors expressed herein do not necessarily state or reflect those of the United States government or any agency thereof.

Available to DOE and DOE contractors from:

Office of Scientific and Technical Information (OSTI)

P.O. Box 62

Oak Ridge, TN 37831

Prices available by calling 423-576-8401

Available to the public from:

National Technical Information Service (NTIS)

U.S. Department of Commerce

5285 Port Royal Road

Springfield, VA 22161

$703-605-6000$ or $800-553-6847$

or

DOE Information Bridge

http://www.doe.gov/bridge/home.html

Printed on paper containing at least $50 \%$ wastepaper, including $20 \%$ postconsumer waste 


\section{Acknowledgment:}

This document was prepared by Energy Alliance Group with the support of the Solar Energy Industries Association (SEIA), the US Department of Energy (DOE), and the National Renewable Energy Laboratory (NREL) pursuant to Task Order 78 Contract Number HI-2-12006-0. Any opinions, findings, conclusions or recommendations expressed herein are those of the author and do not necessarily reflect the views of SEIA or DOE. Neither Energy Alliance Group, SEIA, DOE nor any of their employees or affiliates, makes any warranty, express or implied, or assumes any legal liability or responsibility for the accuracy, completeness, or usefulness of any information, apparatus, product or process disclosed or represents that its use would not infringe privately owned rights. Reference herein to any specific commercial product, process or service by trade name, trademark, manufacturer or otherwise, does not constitute or imply an endorsement, recommendation or favoring by SEIA or DOE. 


\section{Table of Contents}

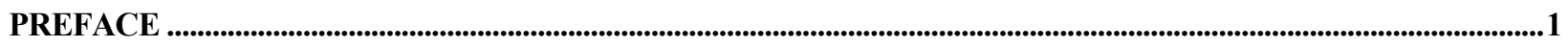

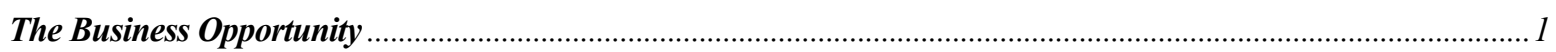

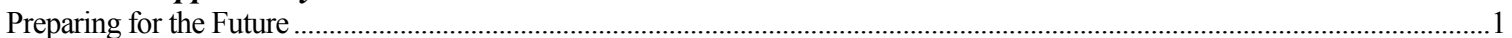

Producing Profits by Satisfying Customers …………………………………………………………………………………...

Why Hasn't this Been Done Before? ……………………………………………………………………………………………......2

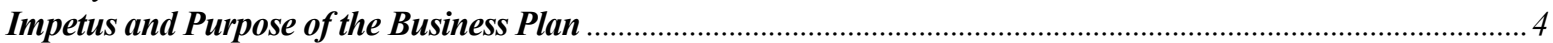

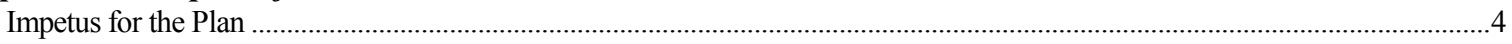

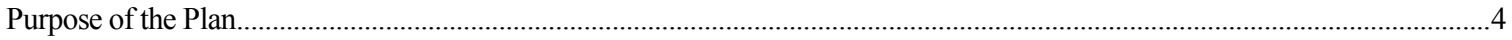

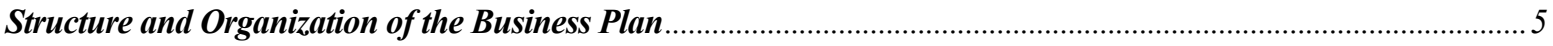

Hypothetical Utility Used as a Reference Point..............................................................................................................................

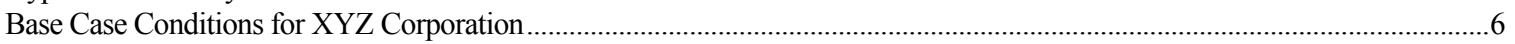

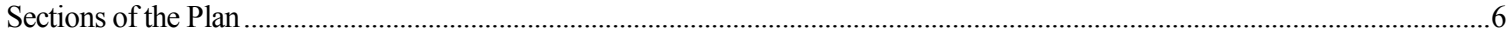

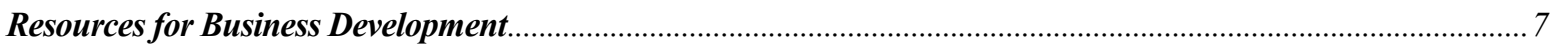

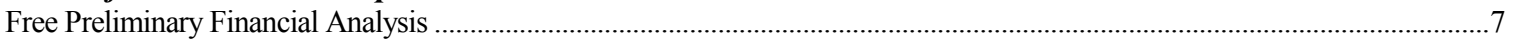

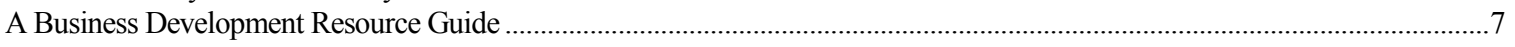

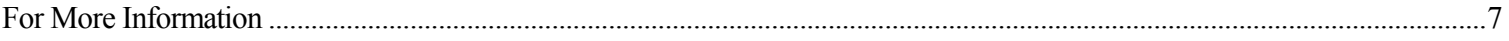

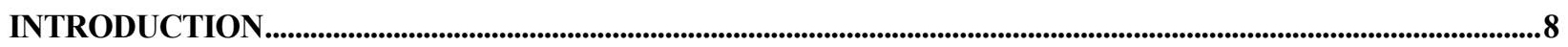

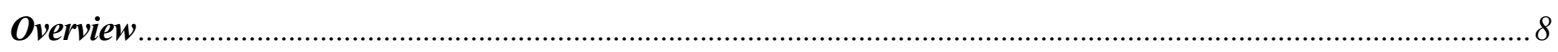

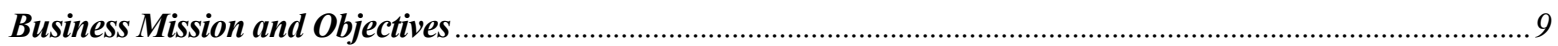

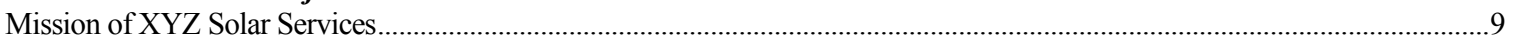

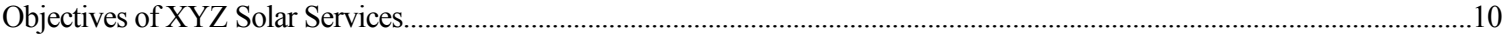

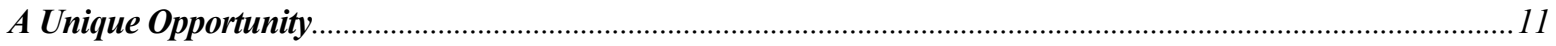

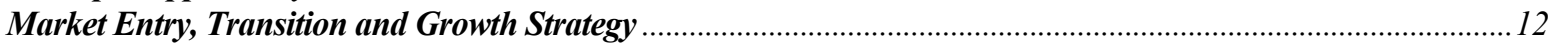

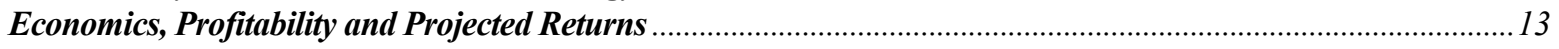

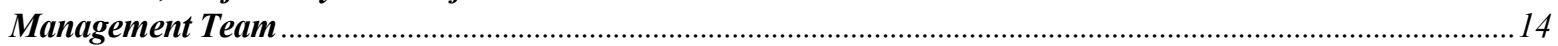

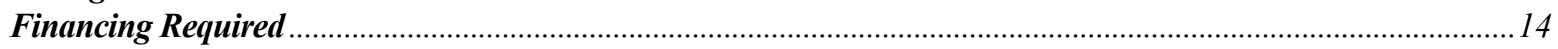

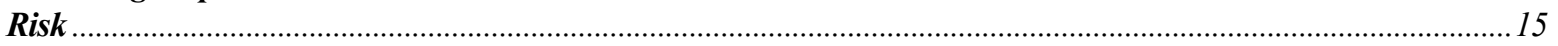

DESCRIPTION OF THE SERVICE.....................................................................................................................................16

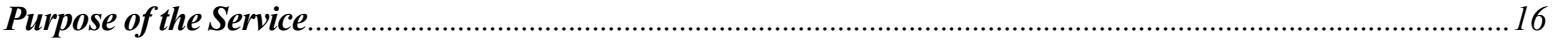

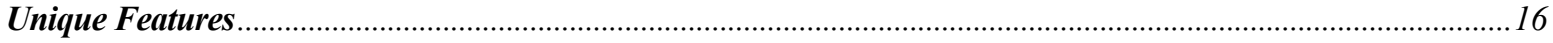

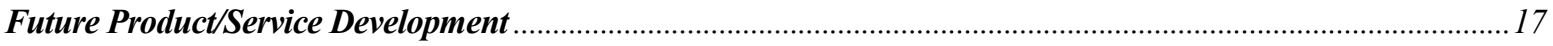

Joint Ventures and Collaborations with Other Utilities ...................................................................................................................

ECONOMICS OF THE BUSINESS.....................................................................................................................................19

Sunshine Not the Most Important Factor in Solar Economics …………………………………………………………………..19

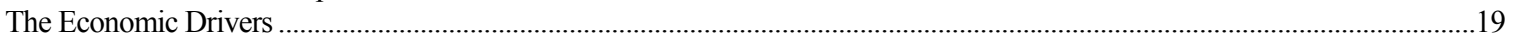

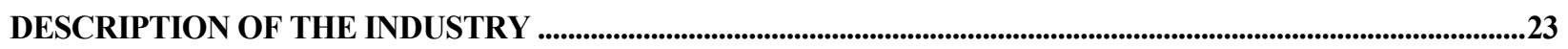

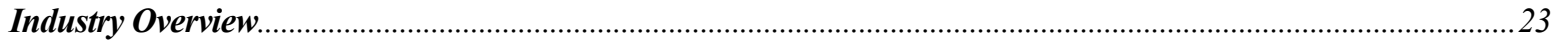

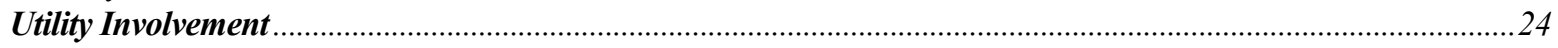

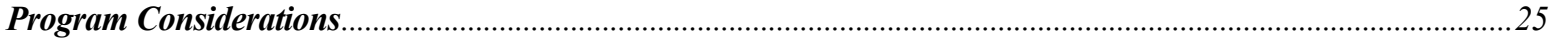

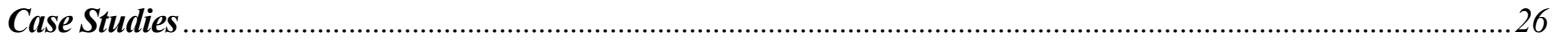

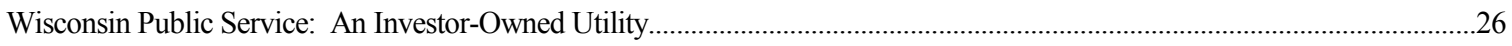

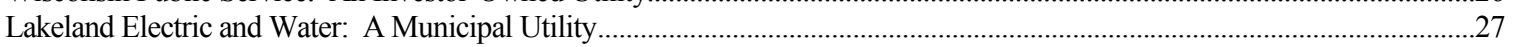

STRATEGIC, STRUCTURAL AND MANAGEMENT ISSUES ........................................................................................33

Trends in the Utility Industry .........................................................................................................................................................33

Congruence with Utility Mission Statement ...............................................................................................................................34 
Structure: Regulated or Unregulated? .....................................................................................................................................34

Staffing: Recruit from the Ranks? ........................................................................................................................36

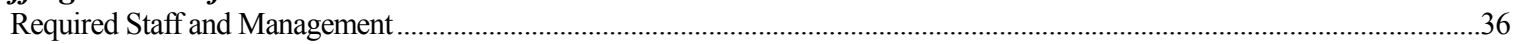

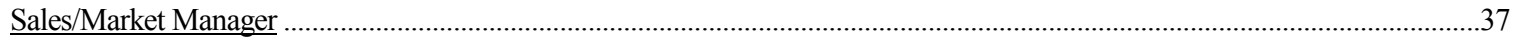

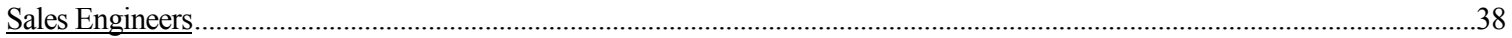

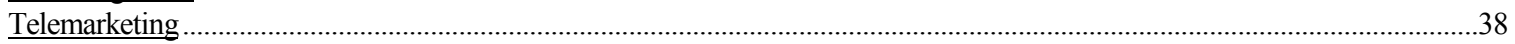

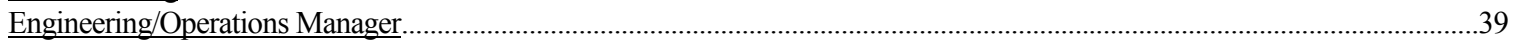

Administrative Support …………………………………………………………………………………………………………39

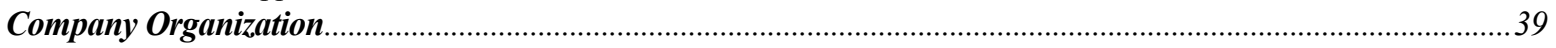

MARKETING PLAN...................................................................................................................................................

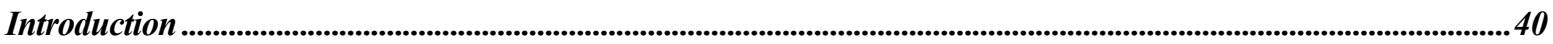

Marketing Background ...........................................................................................................................................................40

Target Market Analysis............................................................................................................................................................4

Market Overview and Size

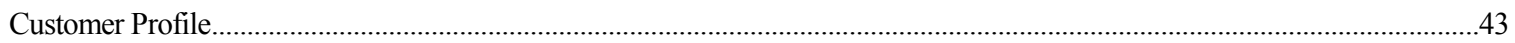

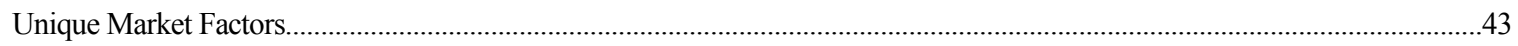

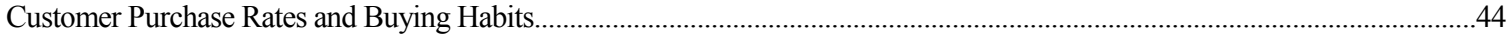

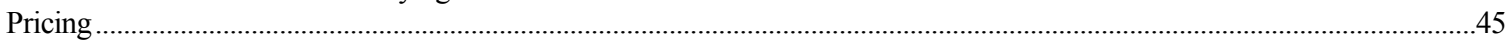

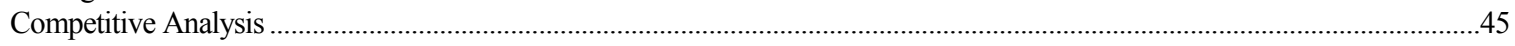

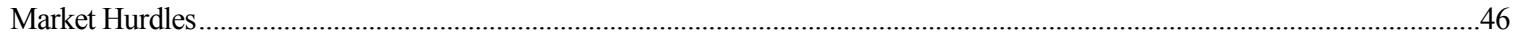

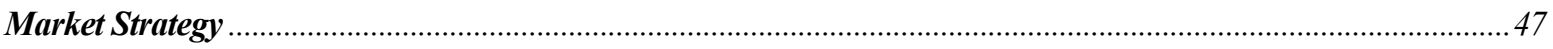

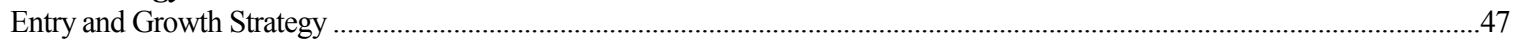

Marketing Communication Strategy ……………………………………………………………………………………....4

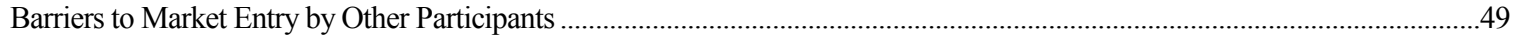

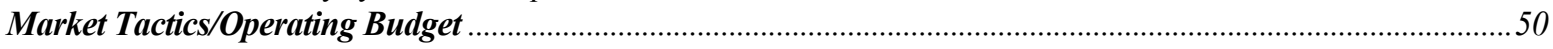

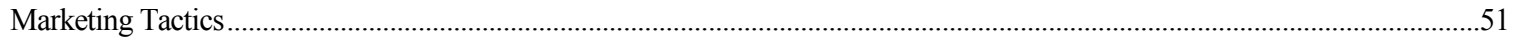

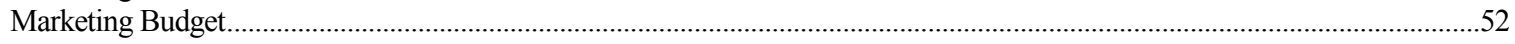

OPERATIONS PLAN .....................................................................................................................................................................................53

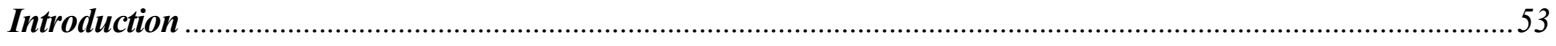

Overview

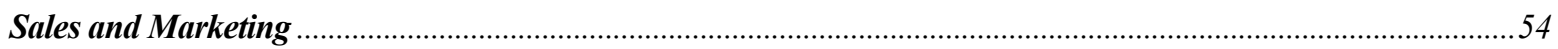

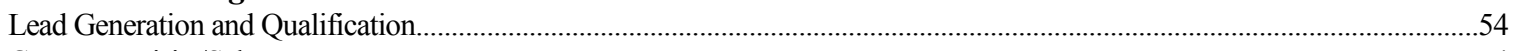

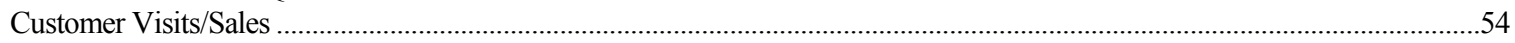

Purchasing

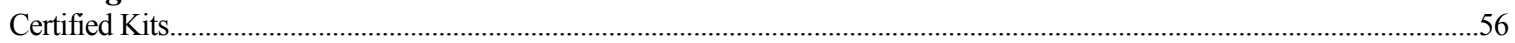

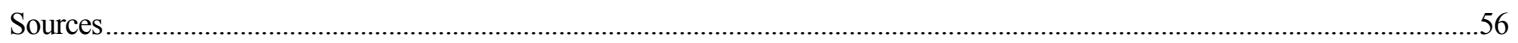

System Assembly, Warehousing and Distribution …………….................................................................56

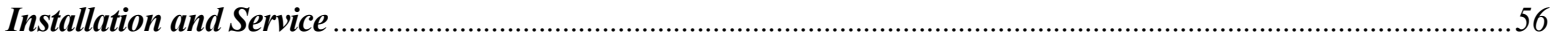

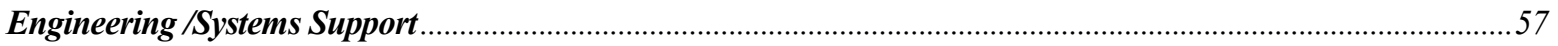

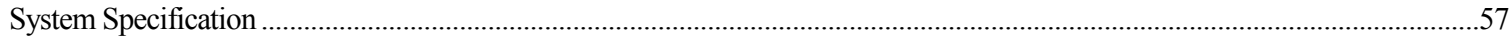

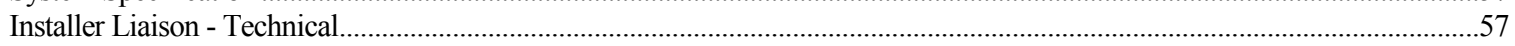

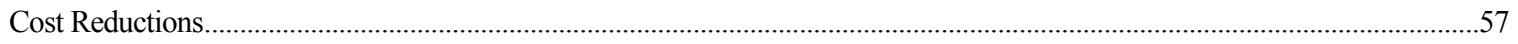

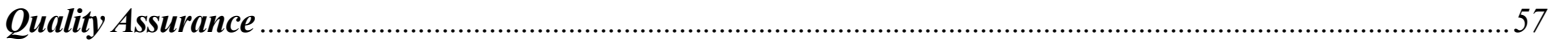

Service and Warranty Strategy ……………………………………………………………………………………………57

Preventive Maintenance Plan ………………………………………………………………………………………………………....58

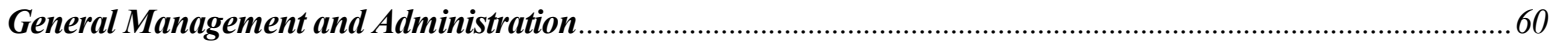

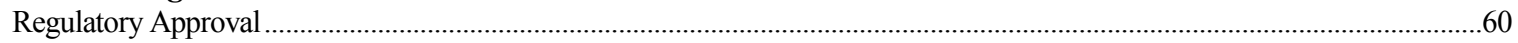

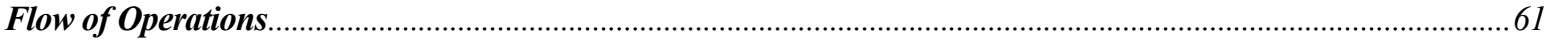

ENVIRONMENTAL AND COMMUNITY ECONOMIC IMPACTS ......................................................................62

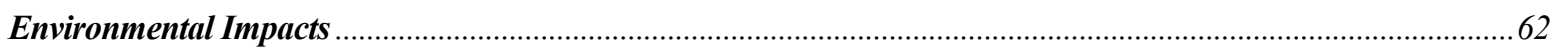

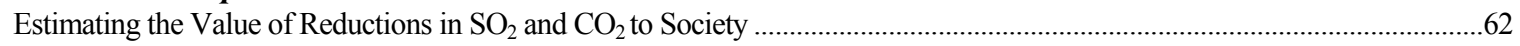

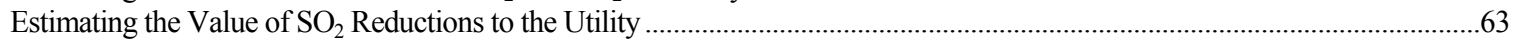

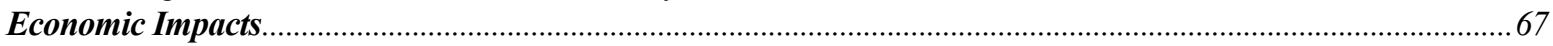

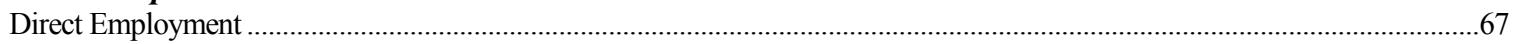

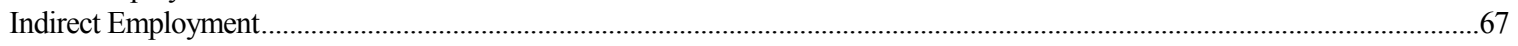


RISKS AND OTHER ISSUES .............................................................................................................................................................69

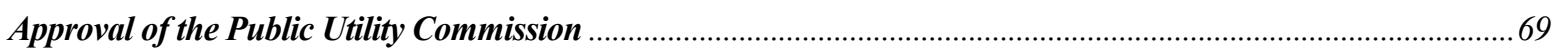

Issue of Negative Impacts on Competitors ................................................................................................................................69

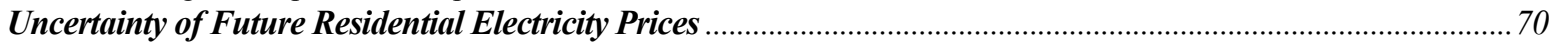

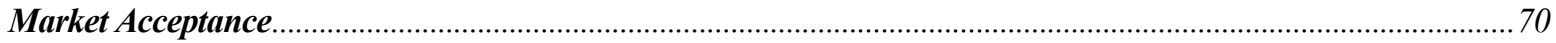

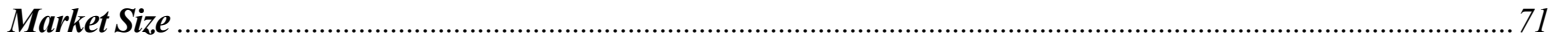

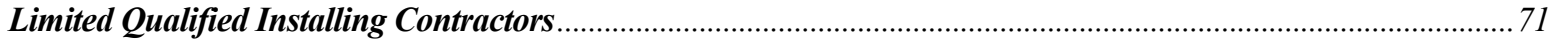

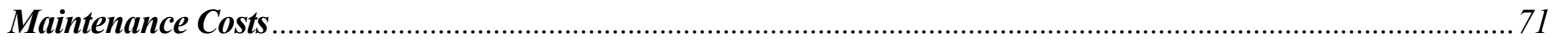

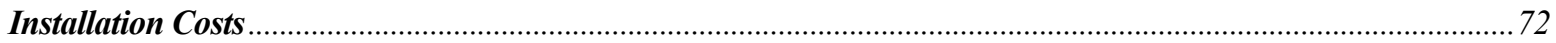

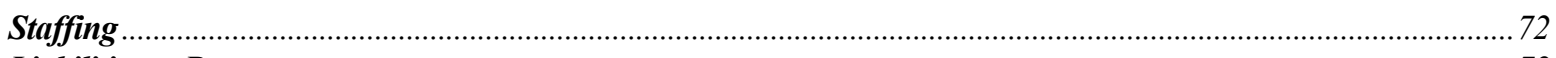

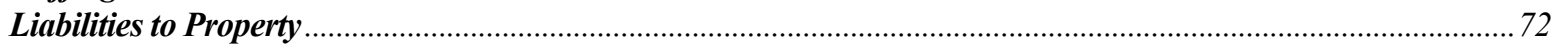

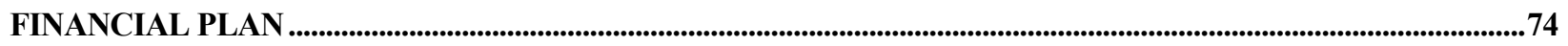

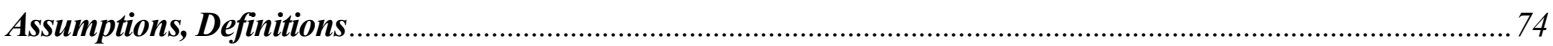

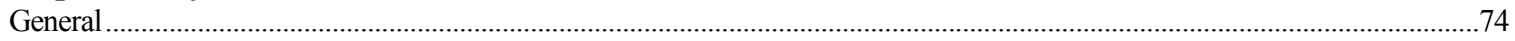

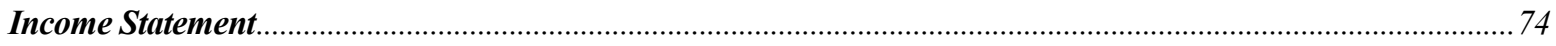

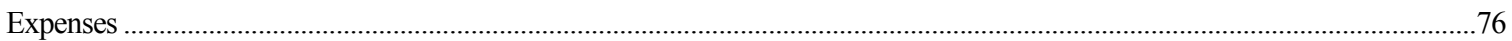

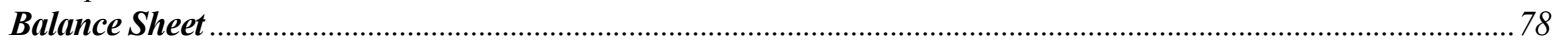

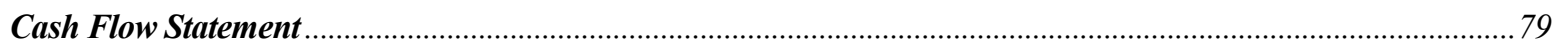

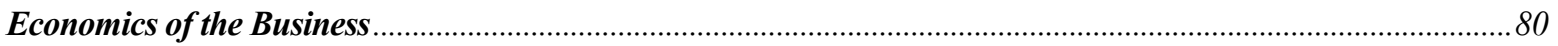

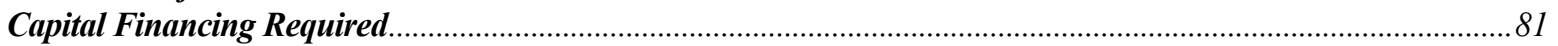

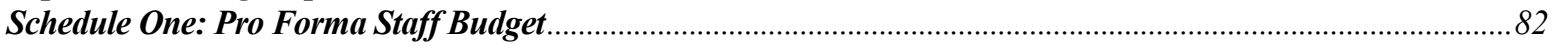

Schedule Two: Equipment Costs and DSM Rebates ................................................................................ 83

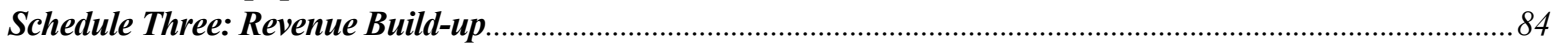

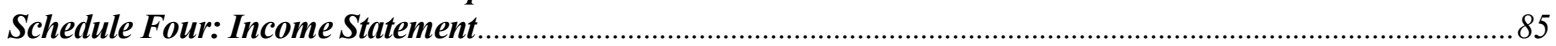

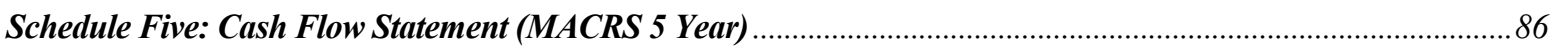

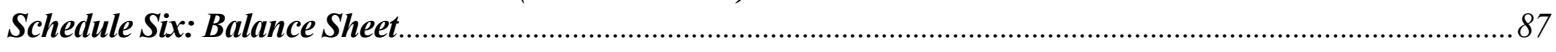

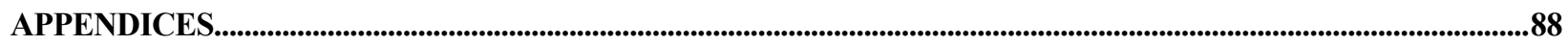

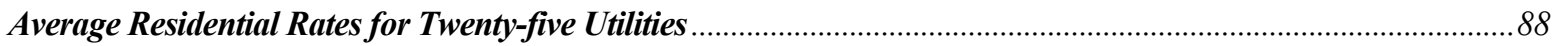

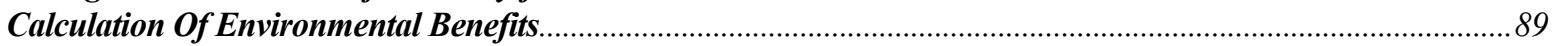

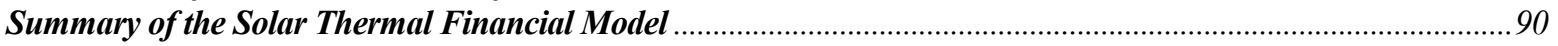

CUSTOMER SURVEY DATA.....................................................................................................................................................94

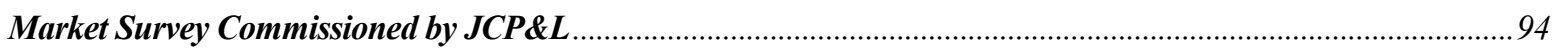

Factors Affecting Solar Water Heating Systems Decision...............................................................................................94

Attitudes Toward Energy Management and the Utility...............................................................................................................94

Evaluation of Response to the Proposed Program ………………………………………………………………………………...95

BUSINESS DEVELOPMENT RESOURCES ..........................................................................................................96

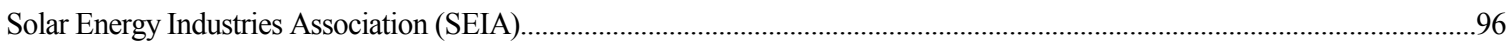

Florida Solar Energy Center (FSEC) ……………………………………………………………………………………....96

ABOUT THE AUTHORS............................................................................................................................................................................99 


\section{Preface}

\section{The Business Opportunity}

\section{Preparing for the Future}

Faced with deregulation and increasingly aggressive competition, utilities are looking for new products and services to increase revenues, improve customer loyalty and retention, and establish barriers to market erosion. With open access now a reality, ${ }^{1}$ and retail wheeling just around the corner, business expansion via new products and services is now the central goal for most utilities in the United States.

It may seem surprising that solar thermal energy as applied to heating domestic hot water - an idea that has been around for a long time - offers what utilities and their residential customers want most in a new product/service. This document not only explains how and why, it shows how to get into the business and succeed on a commercial scale.

Structured as a business plan, the "Business Opportunity Prospectus for Utilities in Residential Solar Water Heating" explains in detail how a residential solar thermal hot water service can satisfy real customer needs and wants... and in the process increase revenues and profits, improve customer loyalty and retention, and help create a formidable barrier to competitive encroachment.

\section{Producing Profits by Satisfying Customers}

This is the first year in which a clear majority of the utility industry has committed to expanding beyond traditional service areas. In response to a recent survey, $64 \%$ of utility respondents said they are currently pursuing

1 In April, 1996, the Federal Energy Regulatory Commission ruled that utilities must provide equal access to their power lines. 
customers outside their service area, while $73 \%$ said they plan to get more involved in servicing the other side of the meter. ${ }^{2}$

Utilities are thinking ahead to the point in time when "switching costs" for residential customers may be no higher than the cost of changing a long distance telephone carrier. Given such a future, a critical question derives: How can a utility defend against the seismic loss of its residential market once the concept of franchise service territories disappears?

By providing solar heated hot water under a "solar service agreement" on an end-use pricing basis, a long-term revenue stream is locked into place. The result is that the Solar Water Heating $(\mathrm{SWH})$ service business can produce attractive profits for most utilities in almost any part of the country. It can also help build an effective bulwark against customer loss in a competitive scenario where the only customer franchise is brand loyalty.

Demographics have shifted over the years, and environmental values are now part of mainstream America. Appropriate attention to how environmental values are reflected in product/service deployment can succeed in creating a strongly differentiated brand image. What customers want are environmentally clean and green energy sources, economically delivered by an environmentally friendly utility.

Like smart consumers anywhere, utility customers would rather pay a little less than they are paying now for electrically heated water. And this is just what modern solar technology coupled with end-use pricing can deliver in most parts of the country: clean, safe, reliable solar heated water that costs less than electrically heated water.

\section{Why Hasn't this Been Done Before?}

So why hasn't this been done before? For one thing, although the technology has steadily improved over the years, no one had taken a fresh look at the fundamental economics of solar thermal hot water for a long time. ${ }^{3}$ Instead, most R\&D capital has been spent on improving or analyzing the efficiency and

\footnotetext{
2 "The 1996 Electric Industry Outlook," published by the Washington International Energy Group, pg. 4, 1996.

3 This is being done now because utilities are systematically scrutinizing every potential new product or service and ranking them relative to others in terms of business expansion opportunities.
} 
reliability of the technology. Like the wind power industry, whose economics have quietly improved by a factor of seven over the last 15 years, the cost, quality, and reliability of Solar Water Heating have also steadily improved due to learning curve effects. The result is that Solar Water Heating has come of age as an economically attractive commercial business opportunity for most utilities.

Yet another reason why Solar Water Heating has only recently been recognized as economically attractive is that end-use pricing has never been applied on a large scale by utilities in the residential market. ${ }^{4}$ End-use pricing involves the sale of the solar heated water itself, rather than the sale or lease of equipment that makes it. Service agreements for solar heated water can therefore be perpetual if the service itself is priced correctly, i.e., if it is a little cheaper than the electrically-heated alternative, and if it has continuing value to the customer.

The service revenue stream from a perpetual service agreement is considerably more attractive than the profit margins available from selling or leasing solar equipment.

Solar Water Heating is also easier to sell using end-use pricing because it eliminates customer issues of high first cost and perceived risk that have been major weaknesses in how solar has been marketed in the past. In fact, enduse pricing will significantly increase customer penetration, and this will have a correspondingly positive impact on the economics of Solar Water Heating as a stand-alone profit-making business.

4 At least not in this country. Chauffage, a form of end-use pricing pioneered in France, dominates the residential market for heat. There is strong evidence that chauffage techniques are starting to be applied in the United States for the commercial and institutional markets. 


\section{Impetus and Purpose of the Business Plan}

\section{Impetus for the Plan}

The impetus for this plan grew from a consortium of utilities and industry professionals named the US $\mathrm{H}_{2} \mathrm{O}$ (Utility Solar Water Heating) Initiative. Since 1993, the US $\mathrm{H}_{2} \mathrm{O}$ Initiative has been working to increase the rate of commercialization of SWH by utilities throughout the country. Its members have been actively involved in solar programs, some for many years and on a large scale, and together they contributed a wealth of information used in the development of this business plan.

A primary function of the US $\mathrm{H}_{2} \mathrm{O}$ Initiative is to assist utility professionals by providing information needed to evaluate specific solar water heating programs and businesses. The US $\mathrm{H}_{2} \mathrm{O}$ Initiative is the primary proponent of the end-use pricing concept for SWH outlined in this document and provided the impetus leading to the creation of this business plan.

This plan was researched and prepared by Energy Alliance Group, an international consulting firm whose focus and specialty is new business and product development related to energy services, strategic marketing, and the commercialization of advanced energy-related technologies for utilities in the United States and Great Britain. ${ }^{5}$

Support in conducting the underlying research was provided by the Solar Energy Industries Association (SEIA), the US industry trade group dedicated to expanding the practical application of solar energy in the U.S. and abroad. Funding for the plan was provided by the Department of Energy through its National Renewable Energy Laboratory (NREL) in Golden, Colorado.

\section{Purpose of the Plan}

In addition to carefully defining the business opportunity, this business plan provides a detailed road map for successfully entering and prosecuting the business. As a tool for business development, the plan:

${ }^{5}$ See "Business Development Resource Guide" in Appendix for information on Energy Alliance Group. 
- Explains how most utilities can establish a new and profitable business by providing solar water heating to residential customers on an end-use pricing basis

- Discusses the economics of the business, why it is attractive, what resources are needed to start the business, and the best operational approach to take, and

- Provides a list of resources that will be helpful to utilities wishing to enter the solar thermal hot water business.

\section{Structure and Organization of the Business Plan}

\section{Hypothetical Utility Used as a Reference Point}

The business plan is constructed around a set of market conditions for a "hypothetical utility." However, the attributes of this hypothetical utility are quite realistic and reflective of a large number of investor-owned electric utilities. While using one set of assumptions means that the plan will not precisely match actual conditions for any specific utility, this approach nevertheless offers a compelling benefit to the reader of this business plan.

Starting with a complete "base case" scenario allows a detailed, comprehensive business plan to be constructed. The important relationships between critical elements in the plan are easily exposed and understood. Armed with a thorough understanding of these relationships, any utility can use this plan as an advanced starting point in writing its own business plan, and in successfully launching the business.

The information in this "Business Opportunity Prospectus" can save months of time and speed market entry; reduce staff and consultant time and cut business development costs; and help insure that the critical aspects of the business are fully understood and reflected in the plan, thereby reducing financial risk and maximizing profits from the business. 
As an added benefit, elements of the approach to business development reflected in this plan may be selectively adopted to improve the existing business development process within the utility for any new product or service.

\section{Base Case Conditions for XYZ Corporation}

The following data apply to XYZ Corporation (the hypothetical utility) around which this business plan was constructed:

Name: $\quad$ XYZ Corporation

Location: Southern section of the U.S.

Size: $\quad$ A medium-sized electric utility

Residential Rate: $\quad 8.5$ cents/kWh

(Inside service area)

Residential Rate: $\quad 10.0$ cents/kWh

(Outside service area)

DSM Rebates: None for solar

State Tax Incentives: None for solar

Federal Tax Incentives: 10 percent investment tax credit (ITC) for solar equipment

Name of Subsidiary: $\quad$ XYZ Solar Services

\section{Sections of the Plan}

As a comprehensive business plan, this document contains all of the sections one might expect, organized as follows:

$\square$ Executive Summary

$\square$ Description of the Service

ㄷconomics of the Business 
$\square$ Description of the Industry

$\square$ Strategic, Structural and Management Issues

\ Marketing Plan

$\square$ Operations Plan

$\square$ Environmental and Community Impacts

$\square$ Important Issues

$\square$ Financial Plan

Appendices

\section{Resources for Business Development}

\section{Free Preliminary Financial Analysis}

Recognizing that interested utilities may wish to analyze this business concept for their own set of conditions, US $\mathrm{H}_{2} \mathrm{O}$ is offering free preliminary financial analysis for any interested utility. For more information, please contact Enstar Inc. at telephone (414) 337-0264 or facsimile (414) 339-8634.

\section{A Business Development Resource Guide}

In the Appendix there is a Business Development Resource Guide which identifies various resources and information that would be helpful in establishing and operating a solar business. These resources include a Glossary of Terms, the U.S. Solar Industries Directory of Products and Services, and a Directory of Resources, including financial software to analyze the investment potential of a "Utility Solar ESCO" on an unregulated or regulated basis, software to estimate the environmental benefits, and other important information.

\section{For More Information}

Additional information about this business plan may be obtained by contacting Energy Alliance Group at telephone (617) 522-4815, or facsimile (617) 5225035. 


\section{Introduction}

\section{Overview}

XYZ Corporation has the opportunity to create a new and profitable business providing solar water heating to residential customers on an "end-use" pricing basis. ${ }^{6}$ This service will be marketed inside and outside XYZ Corporation's service territory, and over a 10 year period will return $\$ 38.6$ million in net after tax revenues against gross revenues of $\$ 89.9$ million. $^{7}$ The after-tax Internal Rate of Return (IRR) of the business is 10.25 percent. The potential to generate substantially higher returns exists via ongoing improvements in operations and other techniques discussed in this business plan.

This business will capture a market niche which is directly related to $X Y Z$ Corporation's core business. And it will provide a new "green" service/product choice for existing and new customers while building differentiation and brand loyalty through provision of an environmentally preferred technology on a unique end-use service fee basis. Positive brand imaging effects will be felt on a national basis. Finally, pursuit of this business on a mass market basis will provide valuable experience for marketing future "advanced technology" products and services in the residential sector.

6 "End-use" pricing means that the end-use of energy is sold instead of the energy itself, i.e., hot water, heating, cooling, lighting, and motive power are provided to customers on an end-use basis instead of kilowatt hours, therms, etc. As utilities strive to fit the role of becoming energy service providers, the trend towards end-use pricing will accelerate.

7 Gross revenues exclude interest on cash balances. 


\section{Business Mission and Objectives}

\section{Mission of XYZ Solar Services}

Through a wholly-owned subsidiary called XYZ Solar Services, $X Y Z$ Corporation will provide Solar Water Heating $(\mathrm{SWH})$ to residential customers on an "end-use" pricing basis. XYZ Solar Services will own, install and maintain the solar equipment at the residential customer's home. In return, XYZ Solar Services will charge customers a monthly service fee which will be slightly less than the retail electricity cost savings produced by the SWH system. In other words, the customer will have a slightly positive monthly cash flow.

The solar equipment $X Y Z$ Solar Services will install will be sized to provide approximately 50 to 60 percent of the annual domestic hot water requirements for a family which is a medium consumer of hot water. Customers will experience no difference in the quality of the hot water or how it is provided. When solar energy is insufficient to meet the demand for hot water, the preexisting electric water heater will supplement supply on an auxiliary basis.

For the first year of operation, $X Y Z$ Solar Services will operate only inside $X Y Z$ Corporation's traditional service territory. In the second year of operation, $X Y Z$ Solar Services will expand outside the service territory by opening a dedicated field office.

The decision as to where to locate the field office will be made at the end of $X Y Z$ Solar Services' first year of operation. In locating the field office, it is expected that the area selected (outside XYZ Corporation's traditional service territory) will have retail electricity rates of 10.0 cents $/ \mathrm{kWh}$ (or higher). Alternatively, the area selected for the field office will have some combination of retail electricity rates, state tax incentives, and/or DSM rebates applicable to solar which will allow selection of an area with retail rates less than 10.0 cents $/ \mathrm{kWh}$ while still achieving the revenues and profits shown in this plan. 


\section{Objectives of XYZ Solar Services}

XYZ Solar Services will achieve a number of important objectives:

- XYZ Solar Services represents an early entry opportunity into a core business which builds directly on the skills and experience of $X Y Z$ Corporation. While today's utilities are working hard to identify new products and services, most of the new product and service ideas initially considered are later rejected because they represent diversification opportunities not strongly related to the core business of an energy utility, i.e., providing energy or its useful end-use to customers (hot water, heating, cooling, lighting, motive power). ${ }^{8}$ In contrast, SWH service is directly within $\mathrm{XYZ}$ Corporation's core business.

$\checkmark$ XYZ Solar Services will enhance XYZ Corporation's image as an environmental leader and help establish an "environmental brand image" to which customers inside and outside the service area will attach significant value. Such differentiation could be a powerful ingredient to future success since deregulation is weakening (and may even eliminate) the concept of a service territory. Absent the advantages of a captive service area, there is widespread agreement that brand imaging will play a vital strategic role in a utility's ability to retain and capture new customers. XYZ Solar Services can play a central role in a brand imaging program aimed at establishing XYZ Corporation as a preferred "green utility."

$\square$ The scale of XYZ Solar Services' activities will create a major renewable energy resource delivering tangible environmental and economic benefits to $\mathrm{XYZ}$ Corporation's customers and society at large. A conservative analysis of environmental benefits from SWH shows that the long-term benefits to society from reduction of $\mathrm{SO}_{2}$ and $\mathrm{CO}_{2}$ are approximately equal to the installed cost of each system ${ }^{9}$. For the number of planned

\footnotetext{
8 Early industry efforts to diversify into unrelated or weakly related new businesses more than a decade ago were largely unsuccessful. The industry seems to have learned from this lesson.

9 See section on "Environmental and Community Economic Impacts".
} 
customers inside the service area, the environmental benefits from XYZ Solar Services' activities are calculated to be $\$ 12.4$ million over the life of the installed equipment. ${ }^{10}$ An additional $\$ 23.6$ million in environmental benefits will occur from SWH service sales outside XYZ Corporation's service area.

- XYZ Solar Services will not rely on DSM rebates from the parent $X Y Z$ Corporation as a source of revenues since the national trend is to move away from the use of rebates. ${ }^{11}$

$\square$ By removing the economic (and other) hurdles associated with using SWH technology, XYZ Solar Services will satisfy an important unmet demand for a significant percentage of the customer base: the demand for an environmentally friendly and cost-effective energy source in the home.

$\square$ XYZ Solar Services will contribute to the refinement of a business development process which will help reposition $X Y Z$ Corporation from a generator-oriented company to a serviceoriented integrator. This in turn will help XYZ Corporation expand into new residential products and services.

\section{A Unique Opportunity}

While other utilities promoting SWH have simply sold or leased solar equipment, $X Y Z$ Solar Services will be one of the first utilities to offer solar heated hot water on an end-use pricing basis. End-use pricing overcomes the customer's first cost objection and fear of being responsible for esoteric technology. In addition to providing differentiation for XYZ Solar Services, the experience gained in marketing end-use pricing will be valuable in marketing future services/products on an end-use pricing basis.

\footnotetext{
${ }^{10}$ Environmental benefits are due to reduced lung disease, decreases in property and crop damage, etc. Assumes average equipment life of 15 years, which is thought to be conservative. See the section: "Environmental and Community Economic Impacts" for a detailed discussion of environmental benefits and their method of calculation.

${ }^{11}$ No DSM savings are used to calculate the financial returns from XYZ Solar Services. These savings, if calculated, monetized, and credited towards XYZ Solar Services, could substantially improve financial returns beyond the $10.25 \%$ IRR predicted.
} 
With the exception of Florida, California and Hawaii, no significant competition exists today in the SWH market. However, driven by deregulation, utilities in every state are intensely focused on developing new products and services. Consequently, XYZ Solar Services will seek to maximize early entry competitive advantages, including volume discounts on equipment, and learning curve advantages in marketing, installation, and maintenance techniques. The strategy, timing and scale of XYZ Solar Services all support the argument that these early entry advantages can be achieved.

\section{Market Entry, Transition and Growth Strategy}

XYZ Solar Services will enter the market in XYZ Corporation's service area in 1997 with a full-time staff. The staff will be expanded in the second year of operation when the field office is opened. Marketing outside XYZ Corporation's service territory will be targeted to an area of the country where retail residential electricity rates are 10.0 cents/kWh or more. A survey of retail electricity rates shows that 11 of the 25 largest investor-owned utilities in the country currently have rates in excess of 11.0 cents/kWh. ${ }^{12}$ These utility areas are capable of supporting a robust SWH business without incentives from state tax credits or utility DSM rebates. Nevertheless, a factor in deciding where to market outside the service area will be the relative availability of state tax incentives and/or DSM rebates for Solar Water Heating. ${ }^{13}$

Over the first 10 years of activity, approximately 7,425 systems are planned for installation inside XYZ Corporation's service area, and another 14,000 outside the service area.

${ }^{12}$ See Appendix: "Average Residential Rates for Twenty-five Utilities (Ranked by Revenues) and Hawaii Electric Company."

${ }^{13}$ See the section on "Economics of the Business" and its subsection: "Financial Incentives from the States" for more information about what incentives are available. 


\section{Economics, Profitability and Projected Returns}

Inside the service territory, customers will pay $\$ 21.50$ per month for Solar Water Heating service, inclusive of a $3.5 \%$ sales tax of $\$ 0.73 /$ month. Outside the service territory customers will pay $\$ 25.00$ per month, inclusive of an estimated $2.5 \%$ sales tax of $\$ 0.49 /$ month. $^{14}$ Net revenues to XYZ Solar Services inside and outside the service territory are $\$ 20.77$ and $\$ 24.51$ per month, respectively. Depending on the size of the family for a given customer, two other service and pricing levels may be developed for both inside and outside the service territory. In this analysis, a family of four is assumed. This planned pricing will produce a net annual utility bill savings for the typical customer of about 5 percent when savings on electricity are taken into account.

The Solar Water Heating service agreement will be for 20 years. There will be no up-front fees, although there will be an early termination fee in the event a customer elects to cancel the service agreement before the end of 20 years. Service agreements will be transferable to new home owners when houses are sold.

On a lifetime basis, total weighted revenues per service agreement are $\$ 3,739$ inside XYZ Solar Service's territory, and $\$ 4,439$ outside the service territory. These amounts exclude the impact of beneficial tax treatment ${ }^{15}$ as well as interest earned on cash reserves. ${ }^{16}$ The weighted average expense per service agreement (including depreciation expenses) is $\$ 2,822 .{ }^{17}$

Starting with total service fees of $\$ 18,696$ from 150 installed systems in year one, service fees expand to approximately $\$ 5.5$ million per year by the 10 th

${ }^{14}$ Since the future location of the field sales office has not yet been decided, the sales tax amount of $2.5 \%$ is only an estimate and may need to be revised up or down accordingly.

${ }^{15}$ Beneficial tax treatment includes the $10 \%$ federal solar credit and the impact of the depreciation tax shield to XYZ Corporation from consolidated losses. The $10 \%$ federal tax credit has a value of approximately $\$ 157 /$ unit. Loss of the $10 \%$ federal ITC would decrease the IRR, but not catastrophically.

${ }^{16} 6.75 \%$ interest earned on excess cash reserves (after year 10 ) generates $\$ 1,416$ in interest on a per system basis, adding substantially to effective revenues and profits.

17 Financial projections are based on a "typical" service fee of $\$ 21.50 /$ month inside the service area and $\$ 25.00 /$ month outside the service area, and an assumed equipment life of 15 years (with corresponding fees/revenues per system of just 15 years). While the equipment is actually expected to last for 20 years, the 15 year revenue/system assumption is used to counterbalance anticipated service agreement defaults, including early termination of service agreements without full payment of early termination fees. 
year of operation. Over a 25 year period, combined service fees of $\$ 89.9$ million will be collected from systems installed in years one through ten. Of that amount, $\$ 27.8$ million will derive from inside the service area and $\$ 62.1$ from outside the service area.

Total after tax income for 25 years will equal $\$ 38.6$ million. $^{18}$ The business produces an after-tax IRR of 10.25 percent on an unleveraged basis. ${ }^{19}$

\section{Management Team}

The management team will be the key to the success of XYZ Solar Services. The team will be comprised of technical and marketing/sales professionals who have an entrepreneurial orientation. The team will start out with two key members: the General Manager and the Sales/Market Manager, and will be augmented by sales, telemarketing and administrative support.

XYZ Solar Services will rely on outside contractors for installations and service. As such, it will benefit from the management inputs and capabilities of those organizations as the business grows. XYZ Solar Services will operate as an integrator by tapping the skills and resources of outside contributors. This will enable XYZ Solar Services to leverage its management resources and run a lean and efficient operation.

\section{Financing Required}

Over the first 10 years of activity, the business will require approximately $\$ 17.7$ million in investment capital on a staged basis. After year 10, the business generates substantial excess cash flows because investing activity ceases. ${ }^{20}$ See "Pro Forma Cash Flow Statement" for year-by-year investment requirements.

\footnotetext{
${ }^{18}$ Note: for purposes of assembling the financials for the business plan, investment activity was assumed to stop after 10 years in order to capture cash flow effects for all installed systems over a maximum 25 year period. In actuality, investment activity would likely continue after year 10, in which case after-tax revenues would be higher than $\$ 38.6$ million.

${ }^{19}$ All investments in solar systems are assumed to be done with $100 \%$ equity.

${ }^{20}$ Investing activity ceases in year 10 only as a concession to calculating the IRR for the business.
} 
Pursuit of this business implies a certain degree of risk. Risks include the uncertainty of market size and market acceptance, uncertainty of installation and maintenance costs, and the need to identify and/or develop qualified installers.

Maintenance costs pose the greatest uncertainty. With respect to this issue, we have assumed annual maintenance costs of $\$ 40$ per system following the first year of installation. Over a 15 -year period this results in total maintenance costs of $\$ 560$ per system, or $\$ 760$ over a 20 -year period. If maintenance costs were $\$ 50$ per month, corresponding to $\$ 950$ over a 20 -year period, the projected IRR for the business would decrease from $10.25 \%$ to $9.73 \%$. Conversely, if maintenance costs are $\$ 30$ per month, the IRR would increase to $10.77 \%{ }^{21}$

Overall, the plan's assumptions upon which the plan is based are considered prudent. Additionally, the operations plan includes specific strategies to minimize risk which will be refined and improved as the business comes up to scale. For a more thorough discussion of risks, see the section on Risks and Other Issues. See also the Marketing Plan and Operations Plan sections for a discussion of other risk-related issues.

${ }^{21}$ Maintenance costs for solar water heating systems vary depending on the type of system installed. $\$ 950$ over a twenty-year life represents the average of a passive system which generally requires very little maintenance because they don't require pumps, controls and other components that may require service over time. 


\section{Description of the Service}

\section{Purpose of the Service}

XYZ Solar Services will provide solar water heating to residential customers on an "end-use" pricing basis. The solar equipment that XYZ Solar Services installs will be sized to provide approximately 50 to 60 percent of the annual domestic hot water requirements for a family which is a medium consumer of hot water.

Customers will experience no difference in the quality of how hot water is provided. When solar energy is insufficient to meet demand, the pre-existing hot water tank will be used as an auxiliary booster to supplement hot water supply. Alternatively, for single-tank systems, a heating element in the single tank will raise water temperature to desired levels when solar energy is insufficient to meet demand.

\section{Unique Features}

$X Y Z$ Solar Services will own, install and maintain the solar equipment at the residential customer's home. In return, XYZ Solar Services will charge customers a monthly service fee which will be slightly less in amount than the retail electricity cost savings produced by the SWH system. In other words, the customer will have a positive net monthly cash flow. 


\section{Future Product/Service Development}

\section{Expansion Into Related Market Segments}

XYZ Solar Services will sell SWH services on an end-use pricing basis to the owner-occupied residential market. As experience is gained and capabilities are proven, $\mathrm{XYZ}$ Solar Services will have the opportunity to understand and address related markets that may offer attractive potential, including:

- Multi-family residential

$\square$ New residential construction

- Residential and institutional swimming pools

$\square$ Government facilities, and

口 Commercial and institutional buildings.

Each of these market segments will have different concerns and "drivers" that will need to be understood for successful market penetration.

\section{Product/Service Expansion}

As $X Y Z$ Solar Services gains experience and operating economies with the expansion of the core SWH business, it may be feasible to begin to provide related services or products that effectively expand the "product line" and offer additional revenue potential. Products or services could be offered on either a sales or leasing basis. Candidates for product or service sales include:

SWH systems (for those who want an outright purchase)

SWH service contracts (for system owners)

$\square$ SWH system design services (for those who want to assemble their own)

- High efficiency heat pumps for air conditioning and heating 
$\square$ Pool heaters

$\square$ Intelligent thermostats and controls

$\square$ Equipment financing

$\square$ Solar space heating

$\square$ Solar thermal process heat, and

$\square$ Energy auditing.

Each product or service will be evaluated based on its revenue and profitmaking potential and its fit with the strategic objectives of XYZ Solar Services.

\section{Joint Ventures and Collaborations with Other Utilities}

One alternative approach to the one planned for penetrating the domestic market outside of local service area would be to form one or more joint ventures or other collaborative arrangements with utilities that are interested in SWH as a business but haven't begun the business development process. Such a venture would enable XYZ Solar Services to expand its business base and ultimately reduce unit costs for systems sold and shipped. This option would be particularly attractive after XYZ Solar Services has refined its marketing and operational capabilities. 


\section{Economics of the Business}

\section{Sunshine Not the Most Important Factor in Solar Economics}

Surprisingly, the relative intensity of available sunshine in different areas of the country is not the most critical factor in determining the economic attractiveness of a solar water heating system. Geographically speaking, there is a close correlation between the amount of sunshine that strikes the earth and groundwater temperature. The more intense the sunshine, the higher the groundwater temperature. But the value of solar hot water increases as groundwater temperature drops. This is because water supply coming from the street water main (at groundwater temperature) must be heated to about 115 degrees $F$, the approximate temperature maintained in most domestic hot water tanks. If the differential between average annual groundwater temperature and the desired tank temperature is high, then a solar heat source can save a great deal of electrical energy. Groundwater temperature is one of several factors other than solar resource that are integral to the evaluation of solar economics. Others include: system type required for a particular climate, installation costs, and operation and maintenance costs.

\section{The Economic Drivers ${ }^{22}$}

The primary driving economic factors are a combination of the cost of the equipment (including installation cost), retail electricity rates, the amount and length of the service agreement, DSM rebates (if any), and state and federal tax incentives. Each of these drivers is briefly discussed below.

${ }^{22}$ For a full discussion of the assumptions used to create the financial statements in this plan, see "Assumptions and Definitions" in the Financial Plan section. 


\section{Cost of Equipment and Installation Labor}

Based on an extensive survey of suppliers, equipment costs range from approximately $\$ 1,000$ to $\$ 2,000$ for both active and passive systems. Labor for installation ranges from $\$ 400$ to $\$ 600$ per system. There may be significant potential to lower these costs, especially the cost of the equipment.

The technology is simple, and from a raw materials standpoint, the cost to manufacture a two-panel solar collector system with a hot water tank is a few hundred dollars. But current manufacturing volumes are low, and production techniques, while improved over past years, are not state-of-the-art.

Hardware costs could drop significantly as the scale of the business increases and manufacturers are able to justify investment in more efficient manufacturing techniques. This in turn will increase profits and return on investment.

\section{Retail Electricity Rates}

Retail electricity rates are a principal driver behind the economics of Solar Water Heating services. Extensive economic modeling ${ }^{23}$ has shown the following:

SWH is economic today in almost any area of the country (without DSM rebates) where the retail rate of electricity is $9.25 \mathrm{cents} / \mathrm{kWh}$ or higher, or where financial incentives like state and federal tax credits and/or DSM rebates are available as an input to the economic equation to compensate for rates below 9.25 cents/kWh.

In fact, most residential customers in the country are serviced by utilities whose retail rates are either 9.25 cents $/ \mathrm{kWh}$ or higher, or who have some combination of available state and federal tax incentives and/or DSM incentives to compensate for rates less than 9.25 cents/kWh. See Appendix: "Average Residential Rates for Largest 25 Utilities" which shows that 12 of the largest 25 utilities have retail rates higher than 9.25 cents $/ \mathrm{kWh}$. 


\section{Amount and Length of the Service Agreement}

The service fee charged to the customer is the principal revenue stream. It should be structured as a perpetual service agreement. However, for the purpose of this business plan, only 15 years of service fee income is assumed. This prudent assumption accounts for customers who may decide to terminate the service without paying the termination fee. It also accounts for service contracts interrupted by the option to switch to natural gas.

\section{DSM Rebates}

Some utilities offer DSM rebates for solar. Amounts vary. While it is generally true that DSM rebates for renewable energy sources are showing greater resiliency in terms of their anticipated continuance in a deregulating environment, a business built on DSM rebates would be a weak business. The proformas in this business plan assume no DSM rebates either inside or outside the service area. Application of such rebates, if available, could improve returns above the projected IRR of $10.25 \%$.

\section{Financial Incentives from the States}

As of the end of 1993, 30 states provided financial incentives for investment in the use of solar thermal collectors and photovoltaic modules and cells, compared with 27 states in 1992 and 15 states in 1991. Among the most common incentives are property tax exemptions and income tax credits for both the residential and business sectors. States like Hawaii and North Carolina, for example, provide a $35 \%$ state tax credit, so these incentives can be significant. For example, a state tax credit which produced a $\$ 500$ reduction in the total initial cost for hardware and installation would increase the projected IRR for the business from $10.25 \%$ to $12.67 \%$. Combined with a DSM incentive, returns could be even higher.

${ }^{23}$ The economic model used to test for sensitivity to retail electric rates and other key variables which drive the economics of solar thermal services was developed by Energy Alliance Group and Wisconsin Public Service Corporation. See Appendix: "A Cash Flow Economic Model for Analyzing Utility/ESCO Solar Water Heating Programs," by C. Bircher, J. DeLaune, C. Lyons. 


\section{Ten Percent Investment Tax Credit from the Federal Government}

There is a 10 percent federal investment tax credit (ITC) for solar thermal systems. Section 1916 of the Energy Policy Act of 1992 (P.L. 102-486) extended indefinitely, retroactive to June 1992, the 10 percent investment tax credit for solar equipment. Commercial entities investing in or purchasing qualified solar energy property can take the credit on up to 10 percent of the investment or purchase price and installation amount. Solar energy property that qualifies for the credit includes "dual use equipment" (equipment that uses both solar and non-solar energy, such as hot water tanks and pipes) only if its use of energy from non-solar sources does not exceed $25 \%$ of its total energy input in an annual measuring period, and only to the extent of its basis or cost allocation to its use of solar energy. 


\section{Description of the Industry}

\section{Industry Overview}

The Solar Water Heating business in the United States has grown into a potent and quality-driven industry that competes successfully on the world market. The emergence of the Solar Rating \& Certification Corporation (SRCC) and the Florida Solar Energy Center (FSEC) have assisted the industry by providing standards, component testing and certification.

The SRCC is a non-profit organization that has developed national operating guidelines and minimum standards for certifying solar water heating systems. FSEC is a 20-year old entity funded by federal, state and private (utility) sources. FSEC has one of two laboratories responsible for testing systems certified by SRCC. These two industry and governmentsupported bodies provide product testing and national certification and, in the case of FSEC, overall industry support through research and contractor training programs.

Broad support is also provided by the Department of Energy (DOE) through the National Renewable Energy Lab (NREL). NREL, located in Golden, Colorado, funds solar thermal technology development and facilitates technology transfer to industry. NREL sponsors many other renewable energy research programs.

For more than twenty years, the Solar Energy Industries Association (SEIA) has been the national trade association representing manufacturers, suppliers, and contractors in the solar thermal and photovoltaic industries. SEIA is dedicated to promoting the use and acceptance of solar technologies in the world marketplace through publications, statistics and marketing data, policy development, education and outreach to the general public. It also sponsors the annual SOLTECH conference, which is the largest solar energy industry conference and trade show in the country. SEIA is made up of three divisions 
and three councils in which over 180 national members and 400 affiliated chapter members participate.

\section{Utility Involvement}

Utilities have been involved with SWH as part of Demand Side Management (DSM) programs for many years. Individual utility programs were designed for local conditions and, for the most part, were individually crafted and operated. The utility industry took a step forward when the US $\mathrm{H}_{2} \mathrm{O}$ (Utility Solar Water Heating) Initiative was begun in 1994. US $\mathrm{H}_{2} \mathrm{O}$ was initiated by a consortium of investor-owned and publicly-owned utilities for the express purpose of advancing the cause of SWH programs throughout the country.

A primary function of the US $\mathrm{H}_{2} \mathrm{O}$ Initiative is to assist utility professionals by providing information needed to evaluate specific solar water heating programs and businesses. In addition, the US $\mathrm{H}_{2} \mathrm{O}$ Initiative is supporting the end-use pricing concept for SWH and is the primary proponent of this document.

The US $\mathrm{H}_{2} \mathrm{O}$ Initiative has monitored and reported on various SWH programs from around the country. Some of them, with lessons learned, include:

\section{Eugene (Oregon) Water and Electric Board (EWEB)}

EWEB initiated their SWH Program in 1990 with the goals of providing a higher level of service in an area of interest to their customers and also to acquire a demand-side electric resource. Through 1994, 275 residential customers have installed solar water heaters.

\section{Boston Edison Company}

Boston Edison is in the beginning stages of a SWH program with the primary objective being customer retention. Research and analysis will precede a pilot program. 


\section{Florida Power \& Light Company}

In 1982, Florida Power \& Light Company (FP\&L) began a solar water heating program offering rebates to customers who replaced electric water heaters with solar water heating systems. By the end of 1993, approximately 45,900 SWH systems had been installed under this program making it one of the largest SWH programs in the United States.

\section{Lessons Learned}

$\square$ Planning is the key a to successful program.

$\square$ Reliance on utility program standards in conjunction with industry standards will lead to the most successful and costeffective installations.

$\square$ Training of all members of the team (installers, inspectors, sales) is vital.

$\square$ Innovation and diversity is essential for progress but can create quality problems when unproven technologies are used.

$\square$ Removing barriers (high first cost, fear of unknown technology) is necessary to ensure customer participation.

\section{Program Considerations}

An important point for a utility considering a Solar Water Heating service business is that the U.S. SWH market is dwarfed by the potential in international markets. Solar technologies, including SWH, are being applied at much higher rates in Caribbean, Central and South American, European and Asian markets. U.S. suppliers maintain they export as much as $65 \%$ of their production, and that the export share of their business is rising. The significance of this to $X Y Z$ Solar Services is that the attention of existing suppliers to the SWH market is not principally focused on the United States.

XYZ Solar Services will have an opportunity to develop the SWH market before potential competition becomes aware and involved. Once engaged in the market, and depending on product and service strategies adopted, XYZ 
Solar Services will also have the potential to participate in the booming international market through joint ventures with aggressive SWH equipment suppliers that are now seeking capital.

Research has shown that the use of solar energy to heat water for domestic, commercial and pool applications is economically feasible in most parts of the United States, not just the sun belt. While solar technologies do not enjoy widespread demand, we believe this is due to lack of purchasing options which address customer concerns, e.g., first cost, reliability, etc. Of note: even with the use of traditional equipment sales and leasing approaches (which have many customer drawbacks) versus the end use pricing approach promoted in this plan, demand has been successfully created by providing information and education about the benefits of the technology to homeowners ( most notably in Florida and California).

\section{Case Studies}

\section{Wisconsin Public Service: An Investor-Owned Utility}

\section{Background and Operating Philosophy}

Wisconsin Public Service Corporation (WPSC) is an investor-owned electric and gas utility which services an 11,000 square mile area of Northeastern Wisconsin and an adjacent portion of upper Michigan. WPSC is working to "create the world's premier energy company." Its Standard and Poors Bond rating remained at $A A+$ during 1995.

The company's strategy is straightforward: to provide customers competitive rates and continually improve products and services. WPSC is working hard to retain existing customers, expand traditional markets beyond its historic service area, and introduce new energy-related products and services. It is in this context that WPSC is pursuing the delivery of solar thermal hot water as a valuable customer service. 


\section{Early History with Solar}

WPSC has taken a highly proactive approach toward renewable energy. Active and passive solar thermal systems have always been covered under the utility's DSM programs. In 1992, the company initiated an incentive program to encourage new solar thermal installations, and this program is still available. However, despite generous rebates and positive grass-roots publicity, the number of new solar water heating systems remained very small.

\section{Focus Groups Shape a Radically New Approach}

Focus groups showed that the problem of customer acceptance was due to three main concerns: high first costs, negative monthly cash flow, and perceived maintenance and reliability risk. To counter these concerns, WPSC is developing its Solar Wise Water Heating Service Program. The service will be marketed to high-use electric water heating customers as an environmentally sound alternative to conventional electric water heating.

\section{End-use Pricing Replaces Equipment Sales and Leasing}

Under the scope of the service, WPSC will take complete responsibility for selecting, purchasing, installing, and maintaining the solar thermal equipment at the customer's home. The customer pays a flat monthly fee, most or all of which is offset by savings. The service fee is included on the customer's electric bill, and WPSC serves as the single contact point for the customer.

\section{Lakeland Electric and Water: A Municipal Utility}

\section{Background}

The City of Lakeland, Department of Electric and Water Utilities (Lakeland Electric and Water) provides electric and water service to the city of Lakeland, Florida, as well as some immediate areas outside the city limits. It is the third largest community-owned utility in Florida. Lakeland Electric and Water is governed by a seven-member City Commission responsible for setting rates and policies which govern day-to-day operations. 
Lakeland Electric and Water generates and distributes more than 650 megawatts of electric power within its service territory. The 250 square mile electric service territory encompasses more than 97,000 customers both inside and outside of Lakeland's city limits. Electricity is sent over more than 120 miles of transmission lines leading to 24 substations where it is distributed to residential, commercial and industrial customers.

Lakeland Electric and Water is committed to progressive change which benefits the ratepayers/owners of the utility, the community at large and the environment. One of the most exciting of these changes is an innovative solar water heating business.

Through distributed generation, Lakeland Electric and Water expects to eliminate many of the costs, wastes, pollutants and other objections to central station power generation. By converting existing solar energy at the customer's location for a competitive price, Lakeland Electric and Water plans to develop an additional means of satisfying customers, thereby generating new revenues and profits for the utility and improving customer retention.

\section{Early History with Solar}

Lakeland Electric and Water has a solid record of solar energy development and promotion. The utility's operations and training facility features a state-ofthe-art solar powered neon-illuminated sign, thought to be the first of its kind. Lakeland installed 20 solar street lights in high visibility areas with descriptive signs explaining the project and the technology to visitors.

As part of its overall support of solar energy, Lakeland Electric and Water has also hosted a state-wide workshop on solar applications featuring representatives from the solar industry, utilities and state and federal officials. In its most ambitious solar program to date, Lakeland Electric and Water has embarked on a pilot program designed to demonstrate "A Cost Effective Solar Water Heating Program for Utilities". 


\section{Business Concept and Operating Philosophy of the Solar Unit}

The business concept and operating philosophy was designed by Lakeland Electric and Water and will be supported, in part, by a grant from the Florida Solar Energy Center. The program has been designed with traditional utility concepts in mind. As such:

$\square$ The utility will own the SWH system installed at the customer location as a form of distributed generation

$\square \quad$ The "generating asset" must (and does) have a long life

$\square$ The SWH system must have minimal impact on the customer relationship, be modular and easy to remove and relocate, and

$\square$ Only metered energy will be sold to the customer with thermal energy converted to a kWh basis and billed monthly.

Lakeland Electric and Water is planning a commercial business that will be profitable without subsidy from the parent utility. The operating philosophy is that, in order to maintain a positive impact on the utility, the business must not detract from the utility's existing electric energy business or its potential gas energy activities. Therefore, the investment rule for the business as a whole is that the value of the solar thermal service business must be greater than the value of fossil-fired generation that it displaces in terms of its impact on shareholders. A target internal rate of return of $14 \%$ to $15 \%$ is being used as the hurdle rate, and preliminary economic analysis indicates that this goal can be met. Although environmental and social benefits will exist and be acknowledged, they will be viewed as positive "externalities" only.

On a per installation basis, Lakeland Electric and Water notes that it has no "obligation to serve" in terms of providing a Solar Water Heating service. If an installation is too expensive, or if the site is inappropriate, e.g., tree cover is too great, the installation is too difficult and costly, etc., Lakeland Electric and Water will not offer the service at that location. This will help insure that the business is profitable. 


\section{Customer Research Identifies Optimal Features of the Service}

While early customer research pointed to generally very positive interest by homeowners, considerable attention was focused on discovering customer concerns in order to reflect these concerns in the design of the service. The following customer concerns were identified:

First cost - customers do not want to pay anything up front, and they may not want to sign a lease agreement for something as simple as hot water delivery

$\square$ Appearance - customers do not want collectors to protrude high above the surface of their roof

$\square$ Service performance - customers are concerned about whether or not they will really receive the services they are paying for; how can a customer know that he/she received a proper level of service?

$\square$ Encumbrance on the home when it is time to sell customers are concerned that a solar system might actually detract from the resale value of their homes

$\square$ Roof penetration - given the large amount of rain experienced in Florida, customers are concerned with anything that must penetrate the roof, such as collector attachments

$\square$ Operating/reliability problems - customers want to avoid problems with system operation.

$\square$ Water temperature consistency - customers have concerns about lack of consistency of water temperature at the tap, and

Fear of general loss - customers have concerns about the effect of windstorms, tree limb damage, vandalism, etc. 


\section{Description of Lakeland Electric and Water's SWH Service}

Designed to address the above concerns, Lakeland Electric and Water will provide a Solar Water Heating service with the following features:

- Lakeland Electric and Water will install and maintain the SWH system at the customer's location with no up-front costs

$\square$ The customer will be charged only for the energy consumed which has been provided by the solar water heater

- The collector design will be of the "skylight type," which is a low profile collector having an attractive appearance; it will be installed near the roof eave versus higher on the roof (this makes it easy to install with a "boom arm")

$\square$ Current plans are leaning toward use of an exterior plastic "downspout" in which will be contained all piping and control wiring, thus eliminating the need to penetrate the roof for purposes of piping (solar collectors will still need to be attached with four bolts, but the degree of invasiveness is less).

- Each system will have a mechanical mixing valve in combination with an anti-scald valve and automatic shut-off controls; this provides three layers of safety to assure that water temperate delivered to the tap is not too hot. It also allows water to be stored at higher temperatures, increasing the effective storage capacity, efficiency and economic performance of the overall system design

a Consideration is being given to a single tank system. The existing hot water tank would be removed and an 80 to 100 gallon single-purpose tank installed; the new tank would have a manufacturer's warranty of 20 years, thus reducing future maintenance costs 
$\square$ The energy produced and delivered would be metered; the same meter would report system performance; the meter would be the AMR type (automatic meter reading); preliminary cost estimates from reliable manufacturers place the cost of this meter at less than $\$ 200$, and

- After an initial start-up phase, there will be no cross subsidies from the regular business.

Based on early research and evaluation, Lakeland Electric and Water believes its business concept is technically viable, economically feasible and beneficial under a variety of potential scenarios. The program is now in its first phase of planning and system definition and will be more fully developed and implemented over the next several years. 


\section{Strategic, Structural and Management Issues}

\section{Trends in the Utility Industry}

All utilities today are in competition at the national level. A merger can change the local and regional competitive landscape overnight. A utility may be surrounded by lackluster competitors whose product and service offerings are little threat. However, market planning inspired by lack of potent local competition only conveys a false sense of security and timing.

Precisely because local competitors are weak, they are more likely to be absorbed by strong, aggressive, nationally-oriented firms with the ability to quickly infuse a full spectrum of effective products and services. Every utility is in a national competition today. Sooner or later, local competitors will develop world class capabilities - or be absorbed firms that have them. Among key trends in the industry, ${ }^{24}$ the following are significant:

- There will be far fewer players in the future, and they will be larger, stronger, and able to steal market-share wherever and whenever the opportunity presents itself.

- Compared to $1995,51 \%$ more of utility respondents to the 1996 utility industry survey performed by the Washington International Energy Group believe they may have to launch a "preemptive strike" against utilities they believe are likely to approach their native load customers.

${ }^{24}$ Most of these trends were presented in a report published y the Washington International Energy Group entitled: "The 1996 Electric Industry Outlook." Contact phone for the report is: (202) 331-9820. 
$\square$ It is an understatement to say that a utility's relationship with customers is undergoing fundamental and rapid change. The debate on customer choice is no longer if it will occur, but when. Half of the utility industry believes that most customers would take advantage of direct access if it were offered.

$\square$ The majority of industry executives believe that un-bundling is increasing compared to a year ago.

\section{Congruence with Utility Mission Statement}

Utility mission statements are undergoing an overhaul. Most now say that they will provide whatever new products and services their customers want which are related to energy. Here is a consensus view of how utilities see themselves in the future:

Based on responses to the Washington International Energy Group national survey, tomorrow's utility company will focus on value-added products and services both inside and outside their traditional service areas. The emerging utility will be an image-oriented, profit-driven merchandiser of soft products and services.

\section{Structure: Regulated or Unregulated?}

Given a desire to proceed with a Solar Water Heating service, should it be provided on a regulated or an unregulated basis? The decision should center on projected profitability.

If the business can produce financial returns which are as high or higher than the regulated business, it should be pursued immediately on an unregulated basis. If the business cannot immediately show higher comparative returns, a transitional strategy should be considered.

XYZ Solar Services has elected to immediately pursue the business on an unregulated basis. While a projected IRR of $10.25 \%$ may be lower than what might normally be required for launching a separate business, three additional 
factors have been considered in arriving at the decision to proceed on an unregulated basis. These are:

$\square$ Ability of XYZ Solar Services to retain customers Completely open competition will result in the loss of residential customers. To the degree that provision of services from XYZ Solar Services retards loss of customer base, the retained marginal revenues should be credited to the value of XYZ Solar Services. While this economic impact is beyond the ability of the authors of this plan to calculate at this time, this effect is considered real and could be economically significant.

\section{$\square$ Reduction of XYZ Corporation's electrical generation cost} structure - While this plan does not attempt to calculate an economic benefit to XYZ Corporation from the DSM effects of replacing a portion of electric resistance heating with solar water heating, such an effect does exist. When the industry is completely deregulated, the beneficial impact which "solar DSM" has will translate into a competitive benefit.

$\square$ Potential to generate higher than projected returns Without taking either of the above effects into consideration, there are ways in which the business can be optimized which hold the potential to substantially increase projected financial returns. However, operational improvements over the base case assumptions can only be achieved through startup and operation as a separate subsidiary where the incentives and motivation exist to maximize performance. Such operational improvements include (but are not limited to) the following:

- Equipment costs might be reduced faster than the assumed schedule of cost reduction achieved via volume sales

- Maintenance costs may prove to be lower than projected

- Outside the service area, it may be possible to sell in locations which provide significant state tax incentives and/or DSM rebates 
- It may be possible to sell into the new construction market, thereby lowering hardware and installation costs significantly (for new construction sales), and

- The assumed duration over which service agreements will last may be more than 15 years, thus increasing revenues.

\section{Staffing: Recruit from the Ranks?}

The following "job descriptions" are generic in nature. Emphasis has been placed on identifying the major attributes a person in a given position will likely need to succeed. It is important to note that XYZ Solar Services will necessarily be an entrepreneurial company relying heavily on certain key individuals responsible for its management and growth. People with a "do whatever it takes" attitude and a strong orientation to understanding and satisfying customer needs will be critical to success. If $X Y Z$ Corporation can find such people within the ranks, they should be considered for XYZ Solar Services. If not, hiring qualified and motivated people from the outside will be necessary to maximize the chances for a successful business.

\section{Required Staff and Management}

\section{General Manager}

The General Manager (GM) will be responsible for all aspects of the management of $X Y Z$ Solar Services and will be accountable for its overall success. The GM will wear several "hats", particularly in the early stages of company development. The functional responsibilities of the GM include:

- General management and overall administration

$\square$ Personnel management

ㄷinancial management

$\square$ Purchasing management

- Engineering management 
$\square$ Quality assurance management, and

$\square$ Operations management.

The most important attribute of the GM will be his/her entrepreneurial capability. As the guiding force for the new business, the GM must provide the vision and drive for his/her staff as well as outside constituents. In short, the GM must manifest strong enthusiasm for building the business and have the flexibility of mind and tenacity that building such a business will require.

The GM position is a salaried position. It should have a significant performance-based bonus component based on meeting or exceeding XYZ Solar Services' business development goals and revenue and profit targets.

\section{Sales/Market Manager}

The Sales/Market Manager is the second most critical individual in XYZ Solar Services after the GM. XYZ Solar Services must be a sales and market driven company and the Sales/Market Manager will be responsible for creating the right company orientation to ensure that is so. The Sales/Market Manager is also responsible for achieving the sales forecast of the company which will determine profitability for XYZ Solar Services.

The Sales/Market Manager must be a skilled sales professional with enough technical background to ensure comfort with the SWH technology. He/she must be an effective sales manager as well as an effective sales person. In the start-up and early development phase of the business, the Sales/Market Manager will be responsible for managing the sales activities of Sales Engineers and Telemarketers, as well as for personally closing some portion of the projected sales forecast.

A final responsibility of the Sales/Market Manager will be the management of marketing responsibilities for XYZ Solar Services. This will be a part-time function and will consist of developing detailed market plans on an ongoing basis and overseeing implementation of selected market communication tactics, both by XYZ Solar Services and in conjunction with XYZ Corporation, the parent utility. In this capacity, the Sales/Market Manager must maintain a good balance between "marketing" and "sales". 
This is a salaried position. If there is a significant sales responsibility, there could be a reduction in base compensation with the addition of a bonus component.

\section{Sales Engineers}

Sales Engineers wear both a technical and sales hat in XYZ Solar Services, but their first responsibility will be to the sales function. Sales Engineers must close deals that result in systems being installed according to XYZ Solar Services forecasts.

The technical function comes into play during the original site evaluation for both sales and installation cost purposes. The Sales Engineer must have enough technical strength to properly evaluate a site for both SWH feasibility and expected installation costs. In addition to site qualification and cost estimating, the Sales Engineer must be able to conduct a post-installation system evaluation and certification. Finally, the Sales Engineer must be able to provide technical support to installing contractors, as needed.

The Sales Engineer does not have to be an "engineer", but he/she must be thoroughly grounded in SWH technology and familiar with common problems that can arise in operations.

This is a salaried position with a base plus bonus formula.

\section{Telemarketing}

A major means of contacting and qualifying prospective customers for $X Y Z$ Solar Services will be through the use of telemarketing. Telemarketing staff will have the responsibility to identify and qualify sales opportunities on both a proactive and reactive basis.

This is an hourly position. 


\section{Engineering/Operations Manager}

The Engineering/Operations Manager is an engineering and management position and will assume some of the responsibilities originally held by the General Manager.

This is a salaried position.

\section{Administrative Support}

The Administrative Support function will provide capable, high-level assistance to management and staff. This position will be filled by someone who is capable of running an office, is comfortable with new challenges, and can complete tasks without much managerial direction. This person must be able to deal effectively with outside parties since (this person) will be the first point of contact to XYZ Solar Services for both customers and contractors.

This may be either a salaried or hourly position, depending on circumstances.

\section{Company Organization}

The organization of a company is normally established after the goals and objectives for the company have been set, and with a view to the specific skill sets that will be needed to make the company grow and prosper. XYZ Solar Services' management team will need to decide on the best organizational structure given its local market challenges and the specific strengths of individual team members. One rule of thumb is to create a very horizontal, highly motivated team with minimal staff additions. Critical staff can be added on a "just in time" basis. Above all, a team with an entrepreneurial outlook and a strong desire to serve and satisfy customers will be critical to the success of XYZ Solar Services. 


\section{Marketing Plan}

\section{Introduction}

For many reviewers of business plans, the market plan is the heart of the business plan, considered to be on a par with the financial plan and the discussion of management. The market plan occupies this position of importance because, in most cases, it is the quality and depth of the firm's marketing programs and the marketing skills of its management team that determine a company's success.

Developing a good market plan is part art, part science. This section addresses the key elements of the market plan and provides a detailed outline of elements that should be included in the specific market plan derived for your unique circumstances.

Developing a good market plan is a disciplined, sequential process of information gathering, decision making, action and evaluation of results. It is an evolutionary and dynamic process. Markets change constantly and companies must change with them to harvest the fruits they offer. The market plan written today must be constantly evaluated for effectiveness and modified as often as necessary to achieve the goals of the company.

\section{Marketing Background}

The first major component of a market plan is the Marketing Background. It is here that we establish the fundamental facts of the marketplace we intend to develop, including such elements as:

$\square$ Target market analysis

$\square$ Company and product review 
$\square$ Customer purchase rates and buying habits

$\square$ Distribution

$\square$ Pricing, and

- Comparative Competitive Analysis

A thorough background evaluation and analysis lets us develop an understanding of the problems and opportunities presented by a specific marketplace.

\section{Target Market Analysis}

Through the ups and downs of government and utility sponsored support, the SWH industry has continued to advance in the U.S. market and thrive in some overseas markets. More than 1.5 million homes and businesses currently have SWH systems. For the last $10+$ years, the industry has made quiet (but significant) strides in technology, manufacturing and service.

The infrastructure to support the SWH business is still in an early growth stage, but current market participants are well positioned to provide quality products at affordable prices. Florida, in particular, supports a thriving residential SWH business that operates successfully without government or utility incentives ${ }^{25}$. This purely commercial model relies on equipment sales to homeowners. It succeeds even without the advantages that XYZ Solar Services will have, such as:

- Consumer confidence inspired by XYZ Solar Services' affiliation with $\mathrm{XYZ}$ Corporation as the parent utility

Elimination of initial purchase price as a barrier, and

- Elimination of homeowner concerns over owning and being responsible for sophisticated, unfamiliar technology.

${ }^{25}$ Florida Power \& Light did offer a DSM rebate for residential SWH systems from 1981-1994. 


\section{Market Overview and Size}

The initial market for XYZ Solar Services will be defined as owner-occupied residences that use electricity to heat water for domestic use. National shipments of electric water heaters have increased $23.6 \%$ in the last 4 years and were up to 3,916,993 units in 1995.

$\begin{array}{cc}\text { Year } & \frac{\text { Electric Water Heaters }}{\text { Shipped }} \\ 1991 & 3,169,965 \\ 1992 & 3,398,605 \\ 1993 & 3,608,740 \\ 1994 & 3,896,839 \\ 1995 & 3,916,993 \\ \text { Source: Gas Appliance Manufacturers } \\ \end{array}$

The market share for electric hot water heaters (versus gas-fired water heaters) has averaged $45.5 \%$ for the last 10 years (GAMA). The 1992 U.S. Census reports $91,947,000$ households in the United States. Of these, $64.2 \%$, or $59,030,000$, are owner-occupied, resulting in a current population of owner-occupied homes with electric hot water heaters of $26,858,000$.

At $\$ 240 /$ year in service revenues, the gross market potential in the U.S. for $\mathrm{XYZ}$ Solar Services is $\$ 6.45$ billion annually.

Additional (un-quantified) potential demand will come from homeowners with natural gas water heaters who are willing to invest in SWH for other than purely economic reasons. In the longer run, XYZ Solar Services will have significant opportunity to develop and sell products and services to other market segments as discussed in the section "Description of the Service". 


\section{Customer Profile}

The initial customer base for XYZ Solar Services will consist of families that are homeowners living in a single-family dwelling. The ideal customer will have the following profile:

- Minimum 4 members in family

- High water users (e.g. babies or teenagers) in family

- Homeowners aware of, and responsive to, environmental issues; ideally are members of an environmental organization that promotes renewable energies, and

- Home has optimal site for SWH; rear south-facing roof or other surface for mounting an SWH collector or free ground area for collector; shade-free.

\section{Unique Market Factors}

Each utility-owned solar services business will have factors that are unique to it in the region in which it intends to do business. XYZ Solar Services will need to plan appropriately for these company-specific market items. Some of the market factors important to XYZ Solar Services include:

- Thirty-three states offer residential, commercial or industrial tax incentives for the purchase or use of various renewable energy systems

Seventeen states offer loans for renewable energy projects

- Seventeen states provide financial grants for the construction of renewable energy projects, and

- The amount of solar insolation available to a SWH collector varies, as does the temperature of water delivered to the domestic water system from municipal water supply mains. 
Temperature and local climactic conditions will impact the specific system design. Freeze-protection will be required for any system installed in a region where freezing temperatures are common. Since even Florida is subject to freezing conditions, the issue is not so much whether to include freeze protection, but how to achieve it. There are various technical solutions which must be evaluated for the specific territory in which XYZ Solar Services will operate. Territory-specific issues which must be considered include:

$\square$ Building styles, and

$\square$ Population density.

Population density will affect the efficiency of the sales, installation and service processes. Initial coverage by XYZ Solar Services will focus on major metropolitan areas with extension to attractive outlying communities on an economically opportunistic basis.

\section{Customer Purchase Rates and Buying Habits}

Except for a few pockets of commercial or utility-subsidized activity around the country, the current market for SWH is largely undeveloped. Although there is an installed base of SWH in the U.S. of more than 1.5 million systems, annual sales in the U.S. are currently measured in the thousands. The target customers identified above are not currently "shopping" for SWH systems because they already have a domestic hot water solution in their home. This represents both a challenge and an opportunity for XYZ Solar Services.

Many studies have shown that the public broadly supports implementation of renewable energy technologies, and that interest in SWH in particular is high. The challenge will be to convert this interest into action in the form of a decision to acquire a XYZ Solar Services SWH system on a perpetual service fee basis. The opportunity will be to develop a new revenue and profit-making business in a market that is essentially untapped. 


\section{Pricing}

XYZ Solar Services will introduce a very new concept to its local marketplace: no purchase of equipment, no ownership worries, and a low monthly service charge that is less than current electricity charges to obtain hot water for the home. The "pricing" for this service cannot be compared to the more common equipment sale pricing common in the industry today.

XYZ Solar Services will provide SWH systems to qualified homeowners on a fixed monthly service fee basis. XYZ Solar Services will retain ownership of the SWH systems. The monthly service fee will be calculated to save the homeowner a modest amount of money (on an annualized basis) compared with what the homeowner would have paid to the parent utility for hot water from an electric water heater. Under the assumed conditions for this document, typical monthly service fees will range from $\$ 21.50$ to $\$ 25.00 /$ month, depending on whether the customer is inside or outside the service area.

The concept of positive cash flow is very important and has been shown to be a key success factor in Florida and California. The service fee will last as long as the contract exists. In effect, the fee is perpetual since XYZ Solar Services will maintain and replace equipment for as long as the contract with the homeowner is in effect.

\section{Competitive Analysis}

In the early stages of market development, the competition for XYZ Solar Services will come primarily from existing solar contractors and from functional substitutes.

Strictly speaking, XYZ Solar Services will be such a unique enterprise and will operate at such scale, that competition will not exist in the conventional sense. Existing SWH contractors operate on an equipment sale basis. They tend to be small, undercapitalized and fragmented in their approach to the market. Most, if not all existing SWH contractors, have other business interests that absorb much of their time and resources. 
As the market is developed by XYZ Solar Services, competition will be more likely from solar service businesses established by other utilities in the wake of market deregulation. It will be important to stay aware of emerging competitors.

Practically speaking, the main competition for XYZ Solar Services is the substitution of functional equivalents for the energy a SWH system might supply. The biggest potential competitor is natural gas, given the relative low cost of this fuel. Electric heat pump water heaters may also offer future competition, but currently they are cost prohibitive.

\section{Market Hurdles}

XYZ Solar Services will have several market hurdles to overcome in developing the SWH market potential inside and outside the $X Y Z$ Corporation's service territory, including:

$\square$ Aesthetics - some customers are sensitive to the appearance of the installed SWH units, particularly the collectors.

$\square$ Property values - potential customers have expressed concern about the possibility that SWH systems may reduce property values. This fear has generally been proven unfounded in markets nationally.

$\square$ Property damage - customers have expressed concern over potential roof damage resulting from the installation or operation of the SWH system. As with the issue of property values, if not addressed and eliminated as a concern, the perception will be a real barrier to sales.

$\square$ Image of the industry - the solar industry had approximately 1,000 companies actively participating in the market as manufacturers, distributors and contractors in the early '80's. When the federal tax credit expired in 1985, the industry contracted, leaving many customers with systems no longer covered by warranties or service. The image of the SWH industry was tarnished by the excesses of that period and 
represents a hurdle for XYZ Solar Services. The engagement of $X Y Z$ Corporation at a visible level will help overcome the negative public perceptions that may still exist among some prospective customers.

- Industry infrastructure - the infrastructure to support sales, installation and service is not uniformly available throughout the country. Due to this lack of infrastructure in some areas, XYZ Solar Services may need to invest resources in identifying and/or training solar contractors and salespeople in the target markets of interest.

$\square$ Gaining acceptance outside the service territory - XYZ Solar Services is expected to enjoy significant good will and market acceptance inside XYZ Corporation's service territory. The goodwill factor will not hold as XYZ Solar Services starts to market outside XYZ Corporation's service territory. New, friendly relationships with local utilities will have to be established in order to benefit from (and build on) the goodwill associated with each local utility.

\section{Market Strategy}

With the marketing background established, market planning efforts shift to developing a market strategy. This portion of the plan will provide the overall guidelines for the company in terms of what it wants to achieve, in what markets, and how it will do so. Specific tactics and plans will follow.

\section{Entry and Growth Strategy}

The market strategy for XYZ Solar Services is to enter and develop the market for SWH in XYZ Corporation's service territory, and then to build on successes and lessons learned by expanding outside the traditional service area. The initial core business targets the residential market, but it will be important for $X Y Z$ Solar Services to evaluate market, product and service extensions on an ongoing basis. XYZ Solar Services has several options that will enable it to achieve its profit and growth goals: 
$\square$ If the target market for SWH within XYZ Corporation's service territory is large enough, $\mathrm{XYZ}$ Solar Services may be able to achieve all of its financial goals simply by developing the core SWH business within its own territory.

- A strategy that relies on adding related products and services within $X Y Z$ Corporation's service area to achieve growth may be viable.

- Expanding outside XYZ Corporation's service area will offer economies of scale. This approach could involve sticking to the core SWH business or emphasizing product and service expansion.

- Joint ventures with other commercial companies (suppliers, distributors, etc.) or other utilities offer tremendous potential to accelerate the development of the SWH business or any business ultimately entered into by XYZ Solar Services.

An added benefit of the strategy to expand outside XYZ Corporation's service territory is that the experience gained by XYZ Solar Services will be invaluable in future efforts to create for-profit businesses that will compete inside or outside traditional service territory boundaries.

\section{Marketing Communication Strategy}

One of the most visible aspects of any market plan is the communication portion, both strategic and tactical. This section deals with the approach XYZ Solar Services will take in communicating with the target market(s). The market communication strategy for XYZ Solar Services will have two main elements:

$\square$ General awareness building, and

$\square$ Focused selling tools to inform and encourage prospective customers to contact XYZ Solar Services for further dialogue. 
A marketing communication strategy attempting to address broad awareness building will seek to rely on activities conducted in tandem with the parent utility. The opportunity to link XYZ Solar Services with XYZ Corporation is very beneficial to $X Y Z$ Solar Services and will be pursued at every opportunity. Any opportunities that XYZ Solar Services has to "piggyback" on parent utility market communication efforts will be fully exploited.

In addition to the type of communications which achieve broad awareness building, XYZ Solar Services will undertake specific, focused market communication activities that have as their main objective identification and qualification of possible customers for XYZ Solar Services. The main thrust of XYZ Solar Services' market communications strategy will be promoting two key messages to potential solar water heating customers. These are:

$\square$ Saving money, and

- Taking positive steps to preserve the environment for future generations (has particular appeal for families).

\section{Barriers to Market Entry by Other Participants}

An important part of any market strategy is to identify, or erect, barriers which prevent competitors from participating in your market. Any company attempting to compete with $X Y Z$ Solar Services will have significant barriers to overcome, including:

- Capital - the capital required to enter the business is high. Most companies will have difficulty raising the required capital.

$\square$ Utility engagement - any company competing with XYZ Solar Services will lack the perceived backing and associated credibility of XYZ Corporation, XYZ Solar Services' parent utility.

Scale - XYZ Solar Services will succeed based on its ability to achieve large scale operations in target markets. By aggressively developing target markets and achieving rapid penetration, XYZ Solar Services will achieve economies of scale 
in selling and operations impossible for a second entrant lacking a local utility affiliation to match.

\section{Market Tactics/Operating Budget}

With the market strategy established for $X Y Z$ Solar Services, the specific tactics that will be employed by the company must be selected and planned. This is a critical step for the company because the tactics required to identify market opportunities and develop them are energy and money intensive. A relatively simple brochure can range in cost from $\$ 5,000$ to $\$ 25,000$ for a single printing, depending on quantity, color, graphics, etc. Delivering the brochures to the target market in a meaningful, effective way can be even more costly.

An important aspect to the tactical part of the market plan is that it embrace a common theme. The theme for the tactics implemented should focus on the benefits the product or service represents to the customer. It should be consistently applied in all market communications employed by the company, from verbal presentations to written materials or electronic media.

A corollary to the concept of "theme" is the idea of repetition. The process of building awareness and desire for a product or service relies on the notion that consumers need to be exposed to a particular message many times before they are inclined to take action. Jay Conrad Levinson, famous for his "Guerrilla Marketing" series, suggests that it takes a consumer as many as 20 exposures to a marketing message to motivate them to take action and buy.

A final important element of the tactical market plan is commitment. Any tactical market plan must be given the opportunity to work. How long? Strict guidelines are difficult, but experience indicates that 3 to 6 months, at a minimum, are required for any market campaign to begin to show clear evidence that it is working (or not working). All market tactics and campaigns should have formal evaluation built into the plan for their implementation. 


\section{Marketing Tactics}

The tactics that XYZ Solar Services will choose to invest in will be a function of the specific parameters the company is working within, including:

- Size and complexity of market opportunity

- Level of awareness of SWH within the target market

- Available capital to invest in marketing activities, and

$\square$ Relative priority of marketing activities within the broader spectrum of goals established by XYZ Solar Services management.

A tactical market plan for any specific solar services business will have to be designed on a case-by-case basis after the marketing background is established, the target market is analyzed, and all relevant internal factors are known. Only then will it be meaningful to specify and plan for the market tactics that will enable a the company to achieve its financial objectives.

Marketing tactics worth considering include:

$\square$ Sales Activity and Management

- Direct sales by company employees

- Selling through channels; independent representatives, distributors and OEM's

$\square$ Strategic alliances; licensing

$\square$ Customer Service

口 Warranties

口 Customer/Market Research

$\square$ Advertising

$\square$ Print

口 Broadcast

$\square$ Product and Company Literature 
$\square$ Brochures

Flyers/utility bill stuffers

$\square$ Catalogs

$\square$ Videos

$\square$ Multimedia presentations on discs and CD's

$\square$ Trade Shows

$\square$ Telemarketing

$\square$ Lead Tracking

$\square$ Direct Mail

$\square$ Education/Seminars

- Event Sponsorship

$\square$ Marketing Public Relations

- Media tours

$\square$ Press releases

$\square$ Promotions

$\square$ On-Line Presence

$\square$ World Wide Web home page

$\square$ Electronic commerce

\section{Marketing Budget}

The tactics presented in the above sections are representative of specific tactics that may be adopted by XYZ Solar Services. In all cases, the creation of an effective market communication strategy with the appropriate supporting tactics can be a very expensive undertaking. The strategy, tactics and budget of XYZ Solar Services will need to be carefully evaluated based on the market potential, the expected return on the investment made, and the specific goals and objectives of both the parent utility and XYZ Solar Services. 


\section{Operations Plan}

\section{Introduction}

The purpose of this section is to outline the main elements of how things will be accomplished within XYZ Solar Services. As in the Market Plan, the detailed Operations Plan that will be necessary for any solar services business will need to be developed on a case-by-case basis using the relevant factors for the business. The Operations Plan should be simple but complete. It will be critical to the profit performance of XYZ Solar Services.

\section{Overview}

The main operations of XYZ Solar Services will be:

- Sales and marketing

$\square$ Purchasing

口 System assembly, warehousing and distribution

$\square$ Installation and service

Engineering and systems support

प Quality assurance, and

$\square$ General management and administration.

The following sections provide an overview of the principal tasks for these functions as well as a listing of the basic tools required in each case. 


\section{Sales and Marketing}

\section{Lead Ceneration and Qualification}

All market communications will have a specific call to action that invites the listener/reader to call $X Y Z$ Solar Services for additional information on the benefits of SWH from XYZ Solar Services. Leads for sales will come from several sources.

The Sales/Market Manager will establish a database marketing program that allows XYZ Solar Services to efficiently manage leads, prospects and customers. Each call-in or mail-in inquiry will represent a sales lead that must be added to the sales database and qualified by XYZ Solar Services. Ideally, $X Y Z$ Solar Services' sales database will start with information available from $X Y Z$ Corporation regarding the location of customers known to heat water with electricity. Such leads will enable the sales team to make proactive telephone calls to introduce, inform and create interest in XYZ Solar Services SWH systems.

\section{Customer Visits/Sales}

The visit by a XYZ Solar Services Sales Engineer will accomplish several objectives, the most important of which are the qualification of the customer and site and the signing of the services agreement that results in installing a $\mathrm{SWH}$ system. Once a sales contract and related paperwork is signed, the Sales Engineer will conduct a site survey to more accurately estimate the cost of the installation. 
The sales/installation activity sequence and tools needed include:

\begin{tabular}{|c|c|c|}
\hline Activity & Responsible & Tools Needed \\
\hline $\begin{array}{l}\text { Lead generation and } \\
\text { qualification }\end{array}$ & Telemarketers & $\begin{array}{l}\text { - Lead lists } \\
\text { - Qualification criteria/checklist } \\
\text { - Scenario scripts }\end{array}$ \\
\hline Site evaluation and sales & Sales Engineers & $\begin{array}{l}\text { - Sales book/materials } \\
\text { - Site evaluation form } \\
\text { - Application/financial history form } \\
\text { - Sales contract with system description } \\
\text { - } \text { and early termination clause } \\
\text { - Savings calculation sheet }\end{array}$ \\
\hline Credit check & Administration & - Credit history for customer; TRW \\
\hline Account set up/approval & GM/Administration & $\begin{array}{l}\text { - Form to notify/activate the utility billing } \\
\text { mechanism to account for revenues } \\
\text { - Customer approval criteria/checklist }\end{array}$ \\
\hline Installation management & Administration & $\begin{array}{l}\text { - Equipment release forms to warehouse } \\
\text { - Contractor release forms to contractor }\end{array}$ \\
\hline Equipment disbursement & Administration & - Form \\
\hline Installation & $\begin{array}{l}\text { Contractor or } \mathrm{XYZ} \\
\text { Solar Service } \\
\text { employee }\end{array}$ & $\begin{array}{l}\text { - Instruction manual } \\
\text { - Certificate of completion }\end{array}$ \\
\hline Installation approval & Sales Engineers & $\begin{array}{l}\text { - Quality Assurance checklist } \\
\text { - Performance test method/equipment }\end{array}$ \\
\hline Contractor payment & GM/ Administration & - $\quad$ A/P systems, forms and procedures \\
\hline
\end{tabular}




\section{Purchasing}

\section{Certified Kits}

XYZ Solar Services will buy kits and components only from manufacturers that are certified by either the Solar Rating \& Certification Corporation (SRCC) or the Florida Solar Energy Center (FSEC). These two organizations represent a major and successful effort on the part of the federal and Florida governments and the solar industry to provide products that are certified to specific performance levels. Certification by either body gives further assurance to the homeowner that the equipment being installed has been subjected to rigorous performance testing and can realize projected savings in energy costs.

\section{Sources}

XYZ Solar Services will buy SWH kits suitable for the local market in as complete a form as possible to minimize the need to buy and stock individual components. A listing of current solar system manufacturers is included in the Appendix. ${ }^{26}$

\section{System Assembly, Warehousing and Distribution}

If kits are not ready to install as they are received from the SWH system supplier, XYZ Solar Services will perform kit assembly. The purpose of the effort will be to insure that system installers will have all of the necessary hardware and information on-hand for a complete, problem-free installation. This will facilitate standardization of procedures and installation efficiency.

\section{Installation and Service}

XYZ Solar Services' employees or independent contractors will perform the critical tasks of installing and maintaining SWH systems for XYZ Solar Services. Installers must be proficient in solar technology. In addition to

26 Note, this list contains both thermal product manufacturers and photovoltaic product manufacturers. 
requiring expertise on SWH principles and hardware, installations require plumbing, electrical, roofing and general carpentry and construction skills.

\section{Engineering/Systems Support}

\section{System Specification}

A SWH system suitable for local conditions will need to be specified. Additionally, engineering must develop the kit concept and all installation documentation necessary to ensure efficient and profitable installation and verification of SWH systems.

\section{Installer Liaison - Technical}

The installers may need occasional support on technical issues associated with installation, operation or maintenance of SWH systems. This engineering function will be handled by the Sales Engineers.

\section{Cost Reductions}

Critical to the success of $X Y Z$ Solar Services business is the successful implementation of planned cost reductions, over time, for both hardware and installation. The engineering function will develop a formal plan for generating cost reductions on a disciplined, structured basis.

\section{Quality Assurance}

\section{Service and Warranty Strategy}

The quality of SWH installations will be assured by relying on:

- Manufacturer's warranties for equipment

- Manufacturer's installation manual,

- Home owner's operation and maintenance manual, 
$\square$ Independent contractors warranties for installation, and

$\square$ XYZ Solar Services verification of proper installations.

The warranty on components will vary as a function of the component and the specific manufacturer. In general, the design life of SWH components is very long if properly maintained. The two largest cost elements in a system are the collectors and the water tank/heat exchanger. Some collectors have a design life of 30 years with an explicit warranty of 10 years. High quality water tanks/heat exchangers can last for 15 years or more if the systems are flushed regularly and anodes are replaced.

Independent installing contractors will provide a minimum 90 day warranty for installations. This period should be sufficient to uncover any problems with the installation, particularly in view of XYZ Solar Services installation verification procedure.

\section{Preventive Maintenance Plan}

Installed systems will receive an annual inspection and preventive maintenance check. Basic system condition will be checked visually and the hot water tank flushed. At 10 years, the anode in the hot water tank will be replaced.

XYZ Solar Services will maintain records for a preventive maintenance program and will dispatch XYZ Solar Services Sales Engineers to perform the maintenance as part of their normal job responsibilities. The Sales Engineer will utilize the annual maintenance visit as an opportunity to introduce new products or services that XYZ Solar Services may introduce from time-to-time.

For other activities, responsibilities and tools needed, see the following page. 
Other activities, responsibilities and tools needed:

\begin{tabular}{|c|c|c|}
\hline Activity & Responsible & Tools Needed \\
\hline $\begin{array}{l}\text { General management and } \\
\text { administration }\end{array}$ & GM & $\begin{array}{l}\text { - Manuals of operation for all key } \\
\text { functions/departments } \\
\text { - Cash flow, forecast and financial } \\
\text { accounting system } \\
\text { - Checklist/plan for all business and } \\
\text { regulatory issues that must be satisfied } \\
\text { to operate as XYZ Solar Service } \\
\text { - Goals and accountability system for } \\
\text { each function }\end{array}$ \\
\hline Purchasing & GM/ Administration & $\begin{array}{l}\text { - Purchasing procedures and forms } \\
\text { - Approved vendor list }\end{array}$ \\
\hline $\begin{array}{l}\text { Subcontractor } \\
\text { identification, screening, } \\
\text { recruitment, training and } \\
\text { relationship management }\end{array}$ & GM & $\begin{array}{l}\text { - Selection and recruitment criteria } \\
\text { - Manual of procedures for operating as } \\
\text { XYZ Solar Service's agent } \\
\text { - Technical training plan }\end{array}$ \\
\hline Contractor scheduling & GM/ Administration & - Scheduling forms; communication \\
\hline Engineering-management & GM & - Engineering procedures and forms \\
\hline $\begin{array}{l}\text { Engineering-specification } \\
\text { of SWH system hardware } \\
\text { and installation procedures }\end{array}$ & GM & $\begin{array}{l}\text { - Installation manual and checklist for } \\
\text { contractors } \\
\text { - Installation/commissioning checklist } \\
\text { - List of local codes; compliance plan }\end{array}$ \\
\hline $\begin{array}{l}\text { Engineering-vendor liaison } \\
\text { for technical issues }\end{array}$ & Sales Engineers & - Engineering procedures and forms \\
\hline $\begin{array}{l}\text { Engineering-cost } \\
\text { reductions in } \\
\text { hardware/installations }\end{array}$ & GM & - Formal cost-reduction plan \\
\hline Sales/Market management & Sales/Mkt Mgr. & $\begin{array}{l}\text { - Sales/market procedures and forms } \\
\text { - Database for prospects, customers } \\
\text { - SWH video }\end{array}$ \\
\hline Warehousing/distribution & GM/ Administration & $\begin{array}{l}\text { - Operations procedures and forms } \\
\text { - Inventory control system }\end{array}$ \\
\hline
\end{tabular}




\begin{tabular}{|c|c|c|}
\hline QA management & GM/ Administration & $\begin{array}{l}\text { - } \text { QA procedures and forms } \\
\text { - System warranty form } \\
\text { - Maintenance plan and checklist } \\
\text { - Home owner's O\&M manual }\end{array}$ \\
\hline QA-installation approval & Sales Engineers & $\begin{array}{l}\text { - Quality Assurance checklist } \\
\text { - Performance test method/equipment }\end{array}$ \\
\hline
\end{tabular}

\section{General Management and Administration}

The General Manager and Administrative Support person will be responsible for setting up all systems to deal with day-to-day effective management of XYZ Solar Services. The systems include:

$\square$ Customer account set up and approval

$\square$ Customer billing

$\square$ Contractor payment

- Financial systems for managing cash flow, forecasts and basic accounting

- Personnel management including hiring, benefits and employee relations, and

$\square$ Goals and accountability for all functions.

\section{Regulatory Approval}

$X Y Z$ Solar Services will need to secure whatever regulatory approvals are required to set up and begin operations. This will be the responsibility of the General Manager. 


\section{Flow of Operations}

The flow of sales and operations for XYZ Solar Services can be summarized with the following:

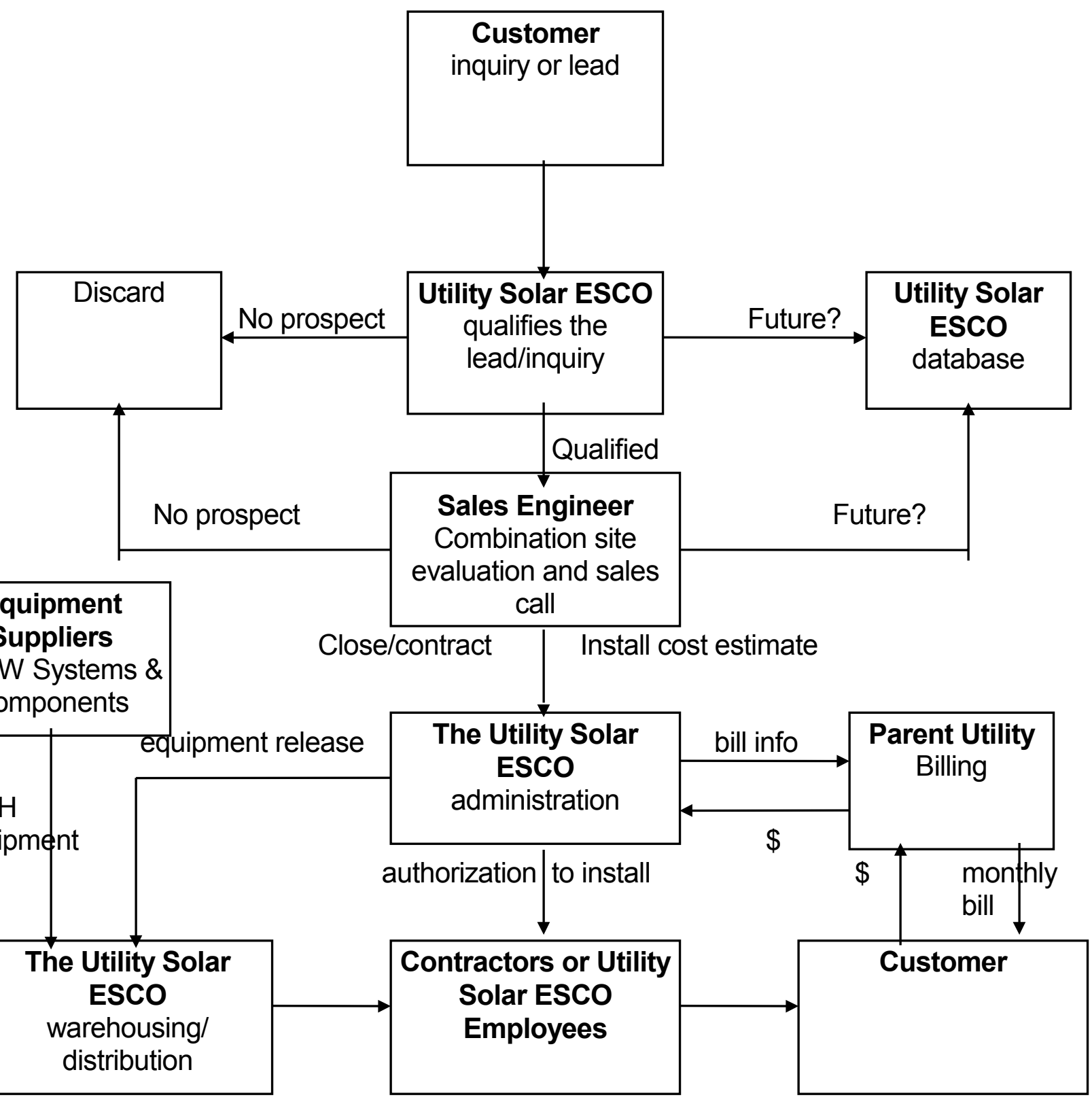




\section{Environmental and Community Economic Impacts}

\section{Environmental Impacts}

\section{Estimating the Value of Reductions in $\mathrm{SO}_{2}$ and $\mathrm{CO}_{2}$ to Society}

Installation of SWH systems from the activities of XYZ Solar Services will generate substantial savings to society in $\mathrm{SO}_{2}, \mathrm{CO}_{2}, \mathrm{NO}_{\mathrm{x}}$, particulate matter (PM), hydrocarbons and other pollutants. Not only is the fuel free and entirely non-polluting once the solar systems are put into production, use of solar energy also decreases the need for construction of electrical generation, transmission and distribution facilities. This results in additional pollution savings. Consequently, the environmental benefits of solar thermal systems, as with any renewable energy source, are quite dramatic.

For the purposes of estimating the positive impacts to the environment from the activities of XYZ Solar Services, only pollution savings due to direct avoidance of the need to burn fossil fuels will be considered. Furthermore, only two principal pollutants, $\mathrm{SO}_{2}$ and $\mathrm{CO}_{2}$, will be considered in the analysis since other sources are more difficult to estimate (and more controversial). ${ }^{27}$

A detailed analysis was made to calculate the dollar savings to society both inside and outside XYZ Corporation's service area for $\mathrm{SO}_{2}$ and $\mathrm{CO}_{2}$. See in the Appendix: "Calculation of Environmental Benefits" for methodology and assumptions. Results are summarized below.

${ }^{27} \mathrm{NO}_{\mathrm{x}}$ emissions may be the next pollution compliance area which will capture the economic value of $\mathrm{NO}_{\mathrm{x}}$ reductions for renewables and/or efficiency. Title I NOx trading is under consideration in Massachusetts and several other states that make up the Northeast Ozone Transport region. State and regional governments are also exploring the use of $\mathrm{NO}_{x}$ trading to address non-attainment areas in Illinois and Houston, Texas. $\mathrm{NO}_{\mathrm{x}}$ trading already exists in California. 
A dollar savings factor of $\$ 0.98$ per $\mathrm{lb}$. of $\mathrm{SO}_{2}$ avoided as the result of displacing electric hot water heaters was obtained by taking an average for published savings factors developed in four key studies. ${ }^{28}$ For $\mathrm{CO}_{2}$, the average savings factor per $\mathrm{lb}$. was $\$ 0.0045875$.

Inside the service area, 7,425 systems will be installed. Over a 25 year period and assuming a 15 year life for each $\mathrm{SWH}$ system, about 7.6 million lb. of $\mathrm{SO}_{2}$ will be saved, reducing air pollution and producing savings to society from improved health, reduced property and crop damage, etc., of $\$ 7.5$ million. Similarly, $\mathrm{CO}_{2}$ savings over the 25 year period will be just over 1 billion lb., with a resulting dollar savings of $\$ 4.9$ million. Total savings from reduced $\mathrm{SO}_{2}$ and $\mathrm{CO}_{2}$ pollution inside $\mathrm{XYZ}$ Corporation's service area will equal $\$ 12.4$ million.

Outside XYZ Corporation's service area, 14,000 systems will be installed, resulting in 14.4 million and 2 billion $\mathrm{lb}$. of $\mathrm{SO}_{2}$ and $\mathrm{CO}_{2}$ savings, respectively. This equates to $\$ 14.4$ million and $\$ 9.2$ million for $\mathrm{SO}_{2}$ and $\mathrm{CO}_{2}$, respectively, for a total $\mathrm{SO}_{2}$ plus $\mathrm{CO}_{2}$ savings of $\$ 23.6$ million outside $\mathrm{XYZ}$ Corporation's service area.

In terms of savings to society, combined savings for $\mathrm{SO}_{2}$ and $\mathrm{CO}_{2}$ total 22.1 million $\mathrm{lb}$. and 3.1 billion $\mathrm{lb}$., respectively. This equates to savings in dollars of $\$ 21.8$ million for $\mathrm{SO}_{2}$ and $\$ 14.1$ million for $\mathrm{CO}_{2}$. Total dollar savings for $\mathrm{SO}_{2}$ and $\mathrm{CO}_{2}$ (both inside and outside $\mathrm{XYZ}$ Corporation's service area) equal $\$ 35.8$ million over 25 years.

\section{Estimating the Value of $\mathrm{SO}_{2}$ Reductions to the Utility}

The Clean Air Act has, through its Acid Rain legislation, provided a mechanism for recovering the economic value of reductions in $\mathrm{SO}_{2}$ which many utilities might well utilize in their overall calculations of net economic inflows to the solar thermal service business. Since the intent in this business plan has been to utilize base case assumptions which are prudent, we have not assumed that $X Y Z$ Corporation will receive any direct economic benefit from $\mathrm{SO}_{2}$ reduction. However, this effective cash inflow should not be ignored

${ }^{28}$ The four studies were published by Pace University, the Bonneville Power Administrations, and the States of Massachusetts and New York. Reference to and key findings from the studies is found in the article: "Pollution Reduction Through Energy Conservation," printed in Vol. 15, No. 1, 1995 issue of Strategic Planning for Energy and the Environment, F. William Payne, editor. Tel. (770) 893-3375. 
if it applies to your specific utility. The legislative background of this benefit and an approach to its calculation are provided on the following page.

\section{Title IV of the Clean Air Act}

Emissions by utilities cause $69 \%$ of $\mathrm{SO}_{2}$ pollution, $35 \%$ of $\mathrm{CO}_{2}$ pollution, and $32 \%$ of $\mathrm{NO}_{x}$ pollution on a national basis. Through Title IV of the Clean Air Act, Congress established the Acid Rain Program. The program seeks to significantly reduce emissions of $\mathrm{SO}_{2}$ and $\mathrm{NO}_{x}$, the primary causes of acid rain. To achieve this goal at the lowest cost to society, the program employs an innovative market-based approach for controlling emissions. In addition, the program encourages pollution prevention through efficiency and renewables like solar thermal hot water.

Title IV sets as its primary goal the reduction of annual $\mathrm{SO}_{2}$ emissions by 10 million tons below the 1980 level. These reductions will be achieved over two phases. Phase I began in 1995 and affects 110 mostly coal-burning electric utility plants located in 21 eastern and midwestern states. Phase II, which begins in the year 2000, tightens the Phase I limits and expands the scope of the program to include most electric utility plants over $25 \mathrm{MW}$.

The Acid Rain Program created a new tradable commodity, the $\mathrm{SO}_{2}$ emission allowance. Each allowance represents an authorization to emit one ton of $\mathrm{SO}_{2}$, i.e., a unit that emits 5,000 tons of $\mathrm{SO}_{2}$ /year must hold at least 5,000 allowances that are usable that year. Each affected source is allocated a specific number of allowances for Phase I and Phase II based on past emissions rates and utilization. Once allotted, allowances may be bought, sold, traded, or banked for use in future years. At the end of each compliance year, a utility must retire one allowance for each ton of $\mathrm{SO}_{2}$ emitted in the preceding year. Holding an insufficient amount of allowances can result in a $\$ 2,000$ per ton fee for non-compliance.

The tradable allowance system will help utilities achieve $\mathrm{SO}_{2}$ reductions at the lowest possible cost by allowing the utilities to choose the most cost-effective compliance strategy. Compliance strategies can include purchasing allowances from other utilities, switching to lower-sulfur fuels, installing scrubbers, and/or implementing efficiency and renewable energy sources. The utility decides which compliance strategy best meets its needs. 
Each year the EPA holds an auction and sells a small portion of allowances (2.8 percent) reserved from the total allowance allocation. The auctions are intended to help signal price information to the market early in the program and to provide a public source of allowances for new utilities that are not allocated allowances. Utilities, environmental groups, and allowance brokers can participate in the EPA auctions. The auctions are being administered by the Chicago Board of Trade.

Renewable energy sources like solar thermal not only create allowances for the utility through the Conservation and Renewable Energy Reserve, they also avoid emissions for which a utility would otherwise need to surrender allowances.

A sample calculation illustrating the value of $\mathrm{SO}_{2}$ allowances which can be produced as a direct result of implementing a solar thermal hot water service business is provided on the next page. 


\section{Example: Calculation of $\mathrm{SO}_{2}$ Avoided Emissions Incentive}

In 1994 a utility installed solar water heating systems in 5,500 residences. Each system saves on average 2,500 kWh each year. The utility will enter the Acid Rain Program in the year 2000, and thus is eligible to earn Reserve allowances until 2000. The value of the reserve allowances is calculated as follows:

5,500 residences x $2.5 \mathrm{MWh} /$ residence/yr. = 13,750 Mw/yr.

$13,750 \mathrm{MWh} / \mathrm{yr} . \div 2.5 \mathrm{MWh} /$ residence/yr. $=28$ allowances/yr.

$\$ 250 /$ allowance $\times 28$ allowances/yr. $=\$ 7,000 / y r$.

Thus, for the six years from 1994 through 1999, the utility could earn $\$ 42,000$ from the Reserve alone. However, the solar water heating systems will continue to add value in the year 2000 and beyond through the avoided emissions incentive, and the benefits from the avoided emissions will be even greater than those from the Reserve.

Assuming the utility's marginal rate of $\mathrm{SO}_{2}$ emissions is $1.2 \mathrm{lbs} / \mathrm{mmBtu}$ (the emission limit for the Acid Rain Program), and has a typical heat rate of $10,000 \mathrm{Btu} / \mathrm{kWh}$, the value of avoided emissions in the year 2000 is:

$1.2 \mathrm{lbs} / \mathrm{mmBtu} \times 10,000 \mathrm{Btu} / 1,000,000 \mathrm{Btu}=0.012 \mathrm{lbs} / \mathrm{kWh}$

$13,750,000 \mathrm{kWh} \times 0.012 \mathrm{lbs} / \mathrm{kWh} \times 1$ ton/2000 lbs = 83 tons = 83 allowances

83 allowances $x \$ 340$ /allowance $=\$ 20,750$

Assuming a 20 year equipment life for each solar system (and retirement of 83 allowances/yr. for 20 years), and a $6 \%$ discount factor, the net present value of the Clean Air Act incentives for this solar water heating project is $\$ 258,000$.

The total present value derived from $\mathrm{SO}_{2}$ pollution reduction is therefore $\$ 42,000+$ $\$ 258,000=\$ 300,000.29$

${ }^{29}$ This sample calculation illustrates how the arithmetic is done, but the trading value of allowances has been significantly less than the values shown in the example. To run this calculation correctly, refer to the Chicago Board of Trade for current prices of allowances. 


\section{Economic Impacts}

\section{Direct Employment}

The majority of energy dollars typically leave the local economy as payments for fuel made by the local utility, and payments to the utility made by its customers. In contrast, financial investments made locally in a renewable energy technology like solar have a very positive impact on job creation.

Direct employment impacts resulting from XYZ Solar Services' activities inside $X Y Z$ Corporation's service area will include the staff of $X Y Z$ Solar Services, installers hired on a subcontract basis, and part-time telemarketers. In the first year of operation, 8 jobs will be created (6 full-time staff and 2 telemarketers). By the fifth year of operation, total staff plus telemarketers will equal 24 . Additionally, approximately 8 full-time installer positions will be created for each year of the 10 year period in which installations are occurring. Similarly, approximately 12 full-time installer positions will be created outside the service area by the time the operation achieves full scale.

New manufacturing jobs, both skilled and unskilled, will also be created as a result of the purchase by XYZ Solar Services of 21,425 systems. These will occur primarily out-of-state since the planned supplier is out-of-state. If a local manufacturing option is pursued as the business achieves scale, there will be additional local direct employment from manufacturing operations.

\section{Indirect Employment}

According to one estimate, the number of jobs per million dollars of annual expenditure in the solar industry is 9.9 for solar water heater manufacture, versus 4.7 for electric utilities. While this is an incomplete comparison of indirect economic effects since there is much more to the business than manufacturing water heaters, on an indirect basis, the economic multiplier effect will undoubtedly create additional local, regional and national employment opportunities. Materials like steel, plastics, glass, copper and aluminum are the essential raw materials required for the manufacture of solar panels, hot water tanks, and associated piping and controls. Finished components may be purchased locally, regionally, or nationally as available. 
Shipping activities will generate more employment. While difficult to quantify, there is no question that the solar thermal hot water business will create jobs indirectly on a local, regional and national basis according to the scale and location of manufacturing, sales, and other activities. 


\section{Risks and Other Issues}

\section{Approval of the Public Utility Commission}

The Public Utility Commission (PUC) of $X Y Z$ Corporation may need to approve XYZ Solar Services' formation. Prior to the PUC's decision, risk will be minimal since significant investment activities would not begin prior to PUC approval. The PUC is likely to take the following issues into consideration:

\section{Issue of Negative Impacts on Competitors}

Issues may arise regarding unfair competition. However, the solar thermal industry is currently small, and the evidence suggests that entry by $X Y Z$ Corporation into the Solar Water Heating service business will spur a large increase in sales of solar equipment and ancillary activities that create direct and indirect employment. For utilities that decide to use trained independent contractors to install and service the systems, entry by XYZ Corporation will have a very positive impact on those contractors by increasing sales of installation and maintenance services.

While there is always the issue of a potentially negative impact on firms who may currently be servicing a market that a utility proposes to enter, it is significant that the Solar Energy Industries Association, the US solar industry trade group, has examined this issue carefully in terms of the likely net impact on its constituents (contractors and manufacturers of solar equipment) and found that entry by utilities would, in the net, be welcomed by the industry. ${ }^{30}$

Consequently, it seems likely that the PUC would be supportive of helping to create a solar energy industry by approving the wholly-owned subsidiary concept.

${ }^{30}$ SEIA also acknowledges, however, that this may not hold true in certain areas of the country where there exist fully mature markets for residential SWH. 


\section{Uncertainty of Future Residential Electricity Prices}

Given the trend toward deregulation, there is considerable uncertainty as to future electricity prices in all market segments. Some predict that price reductions will occur across all market segments equally, and that a new pricing equilibrium will be reached in five years or less. Some predict that price reductions will be very steep for the industrial and large commercial segment and that, consequently, residential rates will rise on a national basis.

If a significant drop in retail rates does occur, there would be two basic effects on XYZ Solar Services. First, existing service agreements which had been priced to create a very small net savings to customers under the presumption of constant future residential rates would produce less "cost avoidance" than projected, leaving some customers with a negative cash flow. Some customers might therefore want to drop the service. Early termination of enough service agreements could have a materially negative impact on the business unit. In that event, an alternative for XYZ Solar Services would be to offer to reduce the monthly service charge. Those customers would still contribute a contribution margin, but the profitability on the affected service agreements would decline. Second, the size of the remaining potential market would effectively shrink, and the level of competition in the remaining attractive markets would likely increase.

\section{Market Acceptance}

A number of obstacles to market acceptance have been identified. These include: awareness of XYZ Solar Services and its services, potential impact on property values and property damage considerations, the poor image of the solar industry, lack of an existing infrastructure (especially for installation and maintenance), the challenge of selling outside XYZ Corporation's service territory, and the sensitivity to overall profitability as a function of retail electricity prices. 


\section{Market Size}

Data on market size are difficult to evaluate and there can be no certainty that the size of the market as estimated by XYZ Solar Services is correct. Additionally, the size of the potential market may contract as natural gas lines are brought to new areas.

\section{Limited Qualified Installing Contractors}

Currently there are only a few qualified installing contractors in $X Y Z$ Corporation's service territory. More will be needed. ${ }^{31}$ To assist prospective contractors in becoming qualified solar contractors, XYZ Solar Services will provide training at its cost. This training will be purchased from the Florida Solar Energy Center, where it has been developed, refined, and applied over more than a decade with great success.

\section{Maintenance Costs}

The plan assumes an annual maintenance/repair budget of $\$ 40$ per year over the 15 year equipment life. Since much of the current generation of equipment lacks a 15 year operating history, the maintenance budget is only an estimate and is lower than historical maintenance costs for older generation systems. The projected improvement (reduction) in maintenance costs is based on the assumption of better quality control procedures now being applied during system manufacture, reliance on available manufacturer warranties for the water tank, the planned application of quality assurance installation procedures, and implementation of a limited preventive maintenance program.

${ }^{31}$ Part of XYZ Solar Services' operating plan calls for building a contracting infrastructure by making training materials from other utility SWH programs available, and by closely supporting participating contractors during their initial learning period. 


\section{Installation Costs}

The average cost of labor for installation has been budgeted at $\$ 600 /$ unit. A number of factors affect installation costs other than local labor rates, including architectural challenges (three story homes versus single story homes), complexity of roof treatment, system type, etc. To keep average installation costs within the budgeted amount, it will be necessary to do one or more of the following: 1. screen installation opportunities and reject those whose complexity would exceed the $\$ 600$ budget, 2 . offer prospective customers an option to pay an installation charge for "non-standard" installations, 3. charge customers more per month when non-standard installations are required, and 4. pay installing contractors a flat $\$ 600$ rate per installation irrespective of difficulty. ${ }^{32}$

\section{Staffing}

It will be important to recruit and motivate highly qualified staff who have the entrepreneurial mindset required to launch a business from the ground up. The recruitment program will carefully define specific skill and experience requirements. While in-house personnel will be considered, an active out-ofhouse recruitment campaign will be funded. Prospective personnel will be required to interview at the top executive level for final approval.

\section{Liabilities to Property}

Installations of SWH systems generally involve the need to penetrate the protective moisture barrier of the roofing system, the need to tie into the domestic water supply, the need to position equipment on and near the home, as do many other home improvement projects. These activities all carry property damage risk, either during installation or at a later date should system problems occur. XYZ Solar Services will carry appropriate liability insurance for these events.

${ }^{32}$ Installations of greater and lesser difficulty would be averaged out by giving contractors a mix of installations of various difficulty. 
Most importantly, installing contractors will receive thorough training in the most advanced methods of flashing and other installation procedures. Experience in Florida, California and elsewhere shows that when these techniques are applied equipment is therefore properly installed and maintained, risk of property damage is minimal. 


\section{Financial Plan}

\section{Assumptions, Definitions}

\section{General}

- Inflation - inflation is assumed to impact revenues and expenses equally; therefore, neither revenues nor expenses are inflated.

口 Income Tax Rate - a marginal income tax rate of $40 \%$ was used for XYZ Corporation (at the consolidated level).

- Equipment Life - the proformas assume a revenue stream from each unit of fifteen (15) years. (The actual system life will likely be longer). For income tax purposes, 5 year MACRS depreciation is applied. This appears in the income statement as depreciation expense, and in the balance sheet as accumulated depreciation.

\section{Income Statement}

$\square$ Incremental Units/Service Agreements Sold - Sales are assumed to occur only during the first 10 years of the life of the business unit in order to facilitate calculation of IRR for the business unit. In fact, it is expected that the business unit will continue after the 10th year and that sales will continue. See Schedule Three "Revenue Buildup" for breakdown of sales inside and outside XYZ Corporation's territory. 
- Revenues - See Schedule Three "Revenue Buildup." As a base assumption, it was decided for marketing reasons that monthly charges to customers for the Solar Water Heating service should be no greater than the monthly savings deriving from displacement of electricity by the SWH system. The $\$ 21.50 /$ month charge assumed for in-territory customers is derived as follows: a. the average electric water heater is assumed to consume $4,989 \mathrm{kWh} / \mathrm{yr}$, b. the average daily output for a SWH system of the type that will be installed is 30,000 Btu/day, c. $30,000 \mathrm{Btu} /$ day $\div 3413 \mathrm{Btu} / \mathrm{kWh}=8.79 \mathrm{kWh} /$ day; $8.79 \mathrm{kWh} /$ day $\times 365$ days $=3,208 \mathrm{kWh} / \mathrm{yr} ; 3,208 \mathrm{kWh} / \mathrm{yr} \times$ $\$ 0.085 / \mathrm{kWh}=\$ 272.71$ savings $/ \mathrm{yr} ; \quad \$ 272.71$ savings $/ \mathrm{yr} \div 12$ $\mathrm{mo} / \mathrm{yr}=\$ 22.73$ savings $/ \mathrm{mo}$; therefore, the monthly charge assumed in the proformas of $\$ 21.50 / \mathrm{mo}$ is, as desired, slightly less than the calculated savings. The $\$ 25.00 / \mathrm{mo}$ charge for outof-territory customers is calculated in a fashion identical to the above, except for the assumption about retail electricity cost. Instead of $\$ 0.085 / \mathrm{kWh}$, substitute $\$ 0.10 / \mathrm{kWh}$. Note: the above computations correlate to a 64 percent solar fraction ("solar fraction" is the annual percentage of total hot water needs that will be supplied by the solar system).

D DSM Rebates/Solar Incentives - No DSM rebates for SWH systems installations are assumed either inside or outside the service area.

- Interest Income - Interest income on cash balances is included. Income is calculated on the average annual balance, which is determined by beginning of year and end of year cash balance projections. Interest is currently projected at the rate of $6.75 \%$ annually.

I Income Tax Expense on Interest Income - Provides for taxation of interest income. 


\section{Expenses}

- Advertising and Promotion - These expenses include costs for video tape production, mailings, and other piggyback advertising that $X Y Z$ Solar Services does in association with $X Y Z$ Corporation.

- Sales Staff, Operations, Administration - See Schedule One "Pro Forma Staff Budget" for detail on staff loading and costs. A "fringe multiplier" of $1.35 \%$ is used to arrive at fully loaded staff salaries. Note that telemarketers are hired on a subcontract basis but are included in the total staff count. See section on Operations for a description of staff responsibilities.

- Travel/Entertain/Confer - Travel for professional staff to attend conferences and meet with suppliers.

$\square$ Rent - Assumes subleasing space from XYZ Corporation. Also, in years two through ten, additional office space is acquired (outside of XYZ Corporation's service territory) to support outside sales. Rent in years eleven through twenty-five is lowered to reflect just the support staff needed to administer existing systems.

Depr Expense - Office Equip. - Office equipment is assumed acquired during the startup phase to enable project development to occur. Therefore, a full year's depreciation expense is taken during startup. It is assumed that staff will require additional equipment on a periodic basis to prepare both for the increases in volume and to establish a field sales office outside the service area in year two. Consistent with $X Y Z$ Corporation's capitalization and depreciation policy, the office equipment is depreciated straight line.

- Depr Expense-Vehicles - Assumes project ownership of a vehicle for use by administrative staff to conduct on-sight inspections. Each vehicle is expected to be useful for five years; thus, a new vehicle is budgeted every five years. Consistent 
with XYZ Corporation's capitalization and depreciation policy, vehicle depreciation is straight line.

$\square$ Utilities - Includes heat and power only. Telephone and fax are embedded in per system marketing and selling expenses.

- Maintenance - Maintenance costs per unit are assumed to be $\$ 40$ per year over the life of the equipment, or $\$ 560$ total per system over the 15 year period of revenue intake. Please note that Sales Engineers will be performing a limited preventive maintenance (PM) program as a normal part of their duties, and those PM tasks are covered under the staff budget.

Insur/Legal/Account/Consulting - Startup costs of $\$ 60,000$ include the cost of developing a SWH Service Agreement, subcontractor agreements, and setting up an accounting system. Year one costs of $\$ 35,000$ is essentially a miscellaneous legal expense category, as are costs of $\$ 25,000$ per year for years two through twenty-five.

$\square$ Depr Expense - Solar Equip. - Assume each unit to be useful for 15 years with regular maintenance.

10\% ITC Solar Tax Credit - Federal tax law allows ten percent of the cost of a solar thermal system to be deducted from the tax liability of the commercial system owner (as a credit) in the first month of the year following the year in which the system was commissioned. In addition, it requires partial subtraction of the amount of the credit for purposes of calculating depreciation, i.e., the amount which is depreciable equals the system cost less one-half of the 10 percent Federal Tax Credit.

$\square$ Income Tax (Expense) Benefit - It is assumed that losses of the business unit are consolidated at the corporate level, and that such losses are used in their entirety during the year in which they occur in order to shelter taxable income of the corporation as a whole. Consequently, no net operating loss (NOL) carry forward treatment is required. 


\section{Balance Sheet}

$\square$ Depreciation - The balance sheet assumes XYZ Solar Services will elect 5 year MACRS depreciation for income tax purposes.

- Cash - Approximately $\$ 144,400$ is required to fund project inception. Additional cash contributions are required in years startup through ten. Cash, therefore, has a zero ending balance through year ten to reflect that only enough cash is invested in the project to fund each year's operations and equipment acquisitions. Cash contributions also increase equity through the capital contribution category. Cash shows positive ending balances once the project begins generating positive cash flow.

$\square$ Other Equipment - the proformas include the purchase, every five years, of a vehicle that will be used to transport employees to inspect installations for quality control and administrative purposes. Note that vehicles required for installation and maintenance are covered under separate budgets for subcontractors responsible for installing and maintaining the systems. The purchase of office equipment to be used in providing administrative support to the business unit is also reflected. For income statement and balance sheet purposes, the vehicles are depreciated over five years straight-line, and the office equipment over three years straight line. For tax purposes, the vehicles are depreciated using the MACRS five year class, while the office equipment uses the MACRS three year class.

Solar Equipment, Labor (for installation) and Freight Cost Per unit cost for the solar equipment is assumed to be $\$ 1,350$ at project inception, with $\$ 600$ in installation costs, and $\$ 60$ in freight/delivery costs. As volume increases and experience is gained in installation technique, these costs are expected to decline. See Schedule Two "Equipment Cost and DSM Rebates." 
$\square$ Deferred Tax Liability - the use of different depreciation methods for "book" and "tax" creates a balance sheet account called "deferred taxes." This deferred tax account is placed in the liabilities section of the balance sheet. In years in which it appears as a negative number on the balance sheet, it is in fact a deferred asset to XYZ Solar Services. In this model it remains as a liability in order to provide the reader with data that is readily comparable from year to year.

$\square$ Capital Contributions - periodic capital contributions, i.e., investments in the business, are fixed in amount and timing to equal any negative cash balance that the combined effects of operations and investments in equipment create, resulting in a zero cash balance at the end of any year.

$\square$ Retained Earnings (Deficit) - Assumes no dividend payments or capital distributions: all earnings remain in the project/business unit.

\section{Cash Flow Statement}

Cash Flow Statement using MACRS Depreciation - This statement begins with Net Income before taxes from the income statement. It then adds back straight line depreciation expense to derive a "cash" income figure. In order to determine the actual cash outflow for income tax payments made in any given year, MACRS depreciation expense is then factored in to derive a new net income number, on which income tax liability for the year is based. MACRS depreciation expense must then be added back because, again, it is not a cash expense. The cash outflows related to equipment appear as investing activities. MACRS accelerates depreciation, thereby creating a valuable tax shield at the consolidated level. This tax shield created by losses is reflected on the MACRS Cash Flow Statement as an "Income Tax (Expense) Benefit." Note: in calculating the IRR, no value was assumed for the business as a going concern, i.e., only after tax outflows and inflows of cash in the form of investments or distributions were used to compute IRR. 


\section{Economics of the Business}

Inside the service territory, customers will pay $\$ 21.50$ per month and enter into a 20 year service agreement for solar heated hot water. There will be no upfront fees, although there will be an early termination fee in the event a customer elects to cancel the service agreement before the end of 15 years. Service agreements will be transferable to new home owners when houses are sold. Outside the service area the monthly fee will be $\$ 25.00$ per month. In both cases the monthly fees are calculated to be just slightly less than the expected cost savings produced by the equipment.

Over the 25 year period included in the financial analysis, total weighted revenues per service agreement inside the service area are $\$ 3,739$ (excluding beneficial tax treatment and interest on cash balances which accumulate in later years) and $\$ 4,439$ outside the service area. Weighted average expenses inside and outside the service area are $\$ 2,822$ per service agreement (including depreciation expenses). ${ }^{33}$ Average benefit from the $10 \%$ solar tax credit is $\$ 157$ per system/service agreement. Average interest from cash balances is $\$ 1,416$ per system/service agreement. This interest income has a very material impact on the economics of the business.

The business produces an IRR 10.25 percent on an unleveraged after-tax basis. This IRR value reflects the use of MACRS depreciation over a 5 year period, which is allowed under the tax code as a special incentive for solar energy systems. A further assumption is made that any losses which occur in $X Y Z$ Solar Services are consolidated at the XYZ corporate level and therefore generate a valuable tax shelter on corporate income. The value of this tax shelter is taken as a reduction to expenses of XYZ Solar Services in order to calculate the true after tax cash inflows and outflows generated by the business on a consolidated basis. See "Financial Assumptions, Definitions."

${ }^{33}$ These projections are based on an assumed equipment life of 15 years. The equipment is actually expected to last for 20 or more years, but the 15 year assumption accounts for contract defaults, including early termination of service agreements without payment of early termination penalty clauses. 
Starting with total service fees of $\$ 18,696$ from 150 installed systems in year one $^{34}$, service fees expand to approximately $\$ 5.5$ million per year by the 10 th year of operation. Over a 25 year period, combined service fees of $\$ 89.9$ million will be collected from systems installed in years one through ten, inclusive. Of that amount, $\$ 27.8$ million will derive from inside the service area and $\$ 62.1$ from outside the service area. Total after tax income for the 25 year period will equal $\$ 38.56$ million.

\section{Capital Financing Required}

Over the first 10 years of activity, the business will require approximately $\$ 17.7$ million in investment capital on a staged basis. After year 10, the business generates substantial excess cash flows because investing activity ceases. ${ }^{35}$ See "Pro Forma Cash Flow Statement (5 Year MACRS)" for year-by-year investment requirements.

${ }^{34}$ Although 150 systems are installed in year 1 , it is assumed that the standing average of installed systems for year 1 is one-half that amount, or $75.75 \times \$ 21.50 / \mathrm{mo} . \times 12 \mathrm{mo} .=\$ 18,696$.

35 Investing activity only ceases as a concession to calculating the IRR for the business. In fact, if investing activity continues past year 10 the IRR may be assumed to be modestly higher than the 10.25 percent calculated for the first 10 years of activity. This is because costs for the first 10 years are declining, but the 10.25 percent IRR reflects weighted average costs over the 10 year period. 


\section{Schedule One: Pro Forma Staff Budget}

SEE FOLLOWING PAGE(S) 


\section{Schedule Two: Equipment Costs and DSM Rebates}

SEE FOLLOWING PAGE(S) 


\section{Schedule Three: Revenue Build-up}

SEE FOLLOWING PAGE(S) 


\section{Schedule Four: Income Statement}

SEE FOLLOWING PAGE(S) 


\section{Schedule Five: Cash Flow Statement (MACRS 5 Year)}

SEE FOLLOWING PAGE(S) 


\section{Schedule Six: Balance Sheet}

SEE FOLLOWING PAGE(S) 


\section{Appendices}

\section{Average Residential Rates for Twenty-five Utilities}

(Ranked by revenue and Hawaiian Electric Co.)

\begin{tabular}{|c|c|c|}
\hline Utility & Rank & Rate $(\boldsymbol{\phi} / \mathbf{k W h})$ \\
\hline Pacific Gas and Electric Co. & $\overline{1}$ & 12.25 \\
\hline Southern California Edison Co. & 2 & 12.07 \\
\hline Commonwealth Edison Co. & 3 & 11.21 \\
\hline Florida Power and Light & 4 & 8.11 \\
\hline TU Electric & 5 & 7.78 \\
\hline Consolidated Edison Co. of New York & 6 & 15.96 \\
\hline Houston Lighting \& Power Co. & 7 & 9.31 \\
\hline Georgia Power Co. & 8 & 7.75 \\
\hline Virginia Electric and Power Co. & 9 & 8.42 \\
\hline Duke Power Co. & 10 & 7.32 \\
\hline Public Service Electric and Gas Co. & 11 & 11.10 \\
\hline Detroit Edison Co. & 12 & 9.35 \\
\hline PECO Energy Co. & 13 & 11.75 \\
\hline Niagara Mohawk Co. & 14 & 11.19 \\
\hline Alabama Power Co. & 15 & 7.18 \\
\hline Carolina Power \& Light Co. & 16 & 8.28 \\
\hline Long Island Lighting Company & 17 & 16.10 \\
\hline Pennsylvania Power \& Light Co. & 18 & 8.20 \\
\hline Connecticut Light \& Power Co. & 19 & 11.19 \\
\hline Baltimore Gas \& Electric Co. & 20 & 8.78 \\
\hline Consumers Power Co. & 21 & 7.10 \\
\hline PacifiCorp. & 22 & 5.80 \\
\hline Union Electric Co. & 23 & 7.53 \\
\hline Ohio Edison Co. & 24 & 10.70 \\
\hline Jersey Central Power \& Light Co. & 25 & 12.00 \\
\hline Average Residential Rate & & 9.94 \\
\hline Mean Residential Rate & & 9.31 \\
\hline
\end{tabular}




\section{Calculation Of Environmental Benefits}

The environmental benefits identified in the section of the business plan on "Environmental and Community Impacts" were calculated using the "REEP" program (Renewable and Energy Efficiency Planning) developed by the U.S. Army Construction Engineering Research Laboratories. The following data sheet shows the calculations involved in estimating the savings in $\mathrm{SO}_{2}$ and $\mathrm{CO}_{2}$ to society. See the Business Resource Guide in this Appendix for information on how to obtain a copy of the program.

SEE FOLLOWING PAGE(S) 


\section{Summary of the Solar Thermal Financial Model}

The "Business Opportunity Prospectus for Utility Solar Water Heating" utilizes a robust financial model developed by Energy Alliance Group and Wisconsin Public Service Company. The model allows any utility to carefully analyze the financial impact of providing solar thermal hot water to residential customers, either as an unregulated business (using a utility-owned "solar ESCO"), or on a regulated departmental program basis.

The Solar Thermal Financial Model analyzes relevant cash flows for the customer, the utility and the utility ESCO. Inputs include the costs and thermal performance of the selected SWH system, financial and rate information from the utility, and details of the customer contract. Options include varying ownership (utility or ESCO), use of equity and/or debt financing, discount rates, customer payment, duration of the customer contract, depreciation schedules and other key parameters.

The Solar Thermal Financial Model computes the net present value (NPV) and internal rate of return (IRR) for the customer, utility and the ESCO. Pre- and after-tax results are tabulated for both a single system and multiple system installations. Sensitivity analyses are built into the Solar Thermal Financial Model -- allowing the impact of 8 key variables to be tested with one run of the model. Results are presented both numerically and graphically.

The Solar Thermal Financial Model can be obtained on a license basis from Energy Alliance Group. For further information, please contact:

Energy Alliance Group

59 Dunster Road

Boston, MA 02130

Tel (617) 522-4815

Fax (617) 522-5035

A free preliminary financial analysis using the Solar Thermal Financial Model is available through the $\mathrm{US} \mathrm{H}_{2} \mathrm{O}$ Initiative. For further information, please contact:

Enstar

1815 Sugar Place

De Pere, WI 54115

Tel (414) 337-0264

Fax (414) 339-8634 


\section{Glossary of Terms}

ABSORBER -- That part of the solar collector which receives the incident radiant energy and transforms it into heat energy.

ABSORPTIVE COATING -- Covers the absorber plate and improves its ability to absorb energy without reflecting it away.

ACTIVE SOLAR SYSTEM -- A system that traps the sun's energy and utilizes a mechanical subsystem to move that energy to its point of intended use for water heating, space heating and possibly space cooling.

AQUASTAT -- Thermostat which measures liquid temperatures.

BRITISH THERMAL UNIT (BTU) -- The amount of heat required to raise the temperature of one pound (one pint) of water, one degree Fahrenheit.

CLOSED LOOP SYSTEM -- System of which no part is vented to the atmosphere or fed with fresh liquid. The system liquid is recirculated.

COIL-IN-TANK- HEAT EXCHANGER -- A coil in a water tank. Most commonly used on solar water heating systems.

COLLECTOR LOOP -- The part of the solar system that has solar collectors. The collector loop may be piped and include other components.

COLLECTOR TILT -- The angle between the horizontal plane and the solar collector plane.

COUNTERFLOW HEAT EXCHANGER -- A self- contained heat exchanger in which the two substances flow in opposite directions.

DHW -- Domestic hot water, hot water used for bathing, washing clothes, dishes, etc.

DIFFERENTIAL CONTROLLER -- A temperature control for solar water heating systems. It measures the difference in temperature between two sensors and turns equipment on and off accordingly.

DIFFUSE RADIATION -- Solar radiation received after its direction has been changed by reflection and scattering in the atmosphere.

DIRECT BEAM RADIATION -- Solar radiation which is not scattered by dust or water droplets. It is capable of being focused and casts shadows.

DIRECT PUMP -- Solar domestic hot water system that uses existing water pressure to fill the collectors.

DOUBLE GLAZED -- Covered by two panes of glass or other transparent material. 
DOUBLE WALL SEPARATION -- Heat exchangers utilizing non-potable heat transfer fluids are separated from the potable water system by use of two walls between the fluids.

DRAIN-DOWN SYSTEM -- A liquid solar collection system in which the collector fluid drains down when the collector system pump is off. Draindown systems circulate a building's domestic

hot water through the collectors and do not normally have heat exchangers.

DRAINBACK SYSTEM -- Liquid system that only fills the collector when the temperature differential is appropriate. The water that is circulated through the collectors is stored in a reservoir.

EXPANSION TANK -- Takes up the overflow created when the heat transfer fluid expands.

FLAT PLATE COLLECTOR -- Converts the sun's radiation into heat on a flat surface within a simple box. Does not use reflecting surfaces, lens arrangements to concentrate the sun's energy.

GLYCOL -- (Propylene Glycol) An antifreeze, heat transfer fluid that is circulated through liquid type collectors.

HEAD -- For pumping considerations, the vertical rise to the highest point in the system. Does not include the horizontal run to that point. Head losses are important for determining flow rates and pump sizes.

HEADERS -- Main passages through which the heat transfer medium enters into or exits from the collector. Also called manifolds.

HEAT EXCHANGER -- A device that is used to transfer heat between fluids and gasses through an intervening metal surface.

HEAT TRANSFER MEDIUM -- Air or liquid that is heated, used to transmit energy to its point of use.

INDIRECT SYSTEM -- A solar heating or cooling system in which the solar heat is collected outside the building and transferred inside using ducts or piping, and usually, fans or pumps.

LIQUID COLLECTOR -- A collector that uses a liquid as the heat transfer medium.

MEAN DAY TEMPERATURE -- Average of the minimum and maximum daily temperatures used to determine the number of degree days.

OPEN LOOP SYSTEM -- Some part of the system is vented to the atmosphere, or the system contains fresh or changeable water. 
PASSIVE SOLAR SYSTEM (Integral Collector Storage/ICS System) -- A solar water heating system whereby water is both heated and stored in within the solar collector. Referred to in the past as 'batch' solar water heaters, these systems are generally used in non-freezing climates and require no pumps or controls.

PHOTOVOLTAICS -- Solar panels used to convert solar energy into electricity.

PUMP STAGING -- A method of placing two or more pumps together to increase flow or overcome head losses. Series-staged pumps are placed in the same line and increase the head. Parallel-staged pumps are placed in two separate lines, feeding a common line and increase the flow rate.

RISERS -- Flow passages (pipes or channels) that distribute heat transfer fluid across the absorber panel in a collector.

SENSOR -- Sensing device that changes its electrical resistance according to temperature. Used in the control system to generate input data on collector and storage tank temperatures.

SOLAR COLLECTORS -- A solar collector is a device designed to absorb incident solar radiation and to transfer the energy to a fluid passing through it.

SOLAR RADIATION -- The sun's energy that comes to earth in the form of direct, diffuse and reflected rays.

SOLAR STORAGE -- A tank of water that stores collected solar energy and holds it until needed.

THERMOSTAT -- Temperature sensing device which is used to switch mechanical equipment on and off.

THERMOSYPHON -- Passive solar systems that rely on the natural convection of liquids to collect energy. Designed with the tank above the collection surface.

TRANSFER FLUID, HEAT -- The heat transfer fluid is the medium, such as air, water or other fluid, which passes through the solar collector and carries the absorbed thermal energy away

from the collector.

UNGLAZED COLLECTOR -- A collector with no transparent cover plate. 


\section{Customer Survey Data}

\section{Market Survey Commissioned by JCP\&L}

As part of its effort to understand the level of customer interest in solar domestic hot water within its service area, Jersey City Power and Light (JCP\&L) commissioned a market research survey. The survey was conducted by the Melior Group during February and March, 1996. The focus was on a proposed solar domestic hot water program that would be offered on a 15 year lease basis to customers. While a lease offering is very different than the service concept proposed in this business plan, the results are nevertheless of great interest.

Two hundred telephone surveys were conducted using an survey form developed by the Melior Group and approved by JCP\&L, General Public Utilities and the Solar Energy Industries Association task force. Summary comments in key areas include:

\section{Factors Affecting Solar Water Heating Systems Decision}

$\square$ Being able to noticeably reduce monthly energy bills was "very important", and

- Environmental and issues are second in importance, but still very important.

\section{Attitudes Toward Energy Management and the Utility}

- $64 \%$ "agreed strongly" to the statement "I make an attempt to use less energy to save money on my utility bills"

- 47\% "agreed strongly" that they "make an attempt to use less energy to benefit the environment", and 
- JCP\&L is perceived as a trusted, reliable service provider. This is an important attribute for JCP\&L or any utility that will be launching a new program in $\mathrm{SWH}$.

\section{Evaluation of Response to the Proposed Program}

- $18 \%$ of respondents would be "very likely" to participate in the lease program if the net cost to the customer was $\$ 10 /$ month, i.e., the monthly lease fee less the savings produced by the system resulted in a cost increase of $\$ 10$.

- $28 \%$ of respondents would be "very likely" to participate in the lease program if the net cost to the customer was $\$ 5 /$ month

- $39 \%$ of respondents would be "very likely" to participate in the lease program if the net cost to the customer was $\$ 0 /$ month (break-even), and

$\square$ Having JCP\&L own and be responsible for the SWH system would have a positive impact on $75 \%$ of customers responding. 


\section{Business Development Resources}

There are a number of excellent resources available to any utility considering a solar domestic hot water business. These include:

\section{Solar Energy Industries Association (SEIA)}

SEIA publishes a comprehensive directory of the solar industry entitled "The U.S. Solar Energy Industry, A Directory of Products and Services". For an updated copy of this document, please call SEIA at (202) 383-2600.

\section{Florida Solar Energy Center (FSEC)}

FSEC publishes a list of resources relevant to the solar industry entitled "Energy Information Sources". For an updated copy of this document, please call FSEC at (407) 638-1000. 


\section{About the Authors}

Chester R. Lyons - Mr. Lyons is president of Energy Alliance Group, a diverse group of senior professionals whose specific expertise and focus is business and product development related to energy services, strategic marketing, and commercialization of advanced energy-related technologies for utilities in the United States and Great Britain. Mr. Lyons has extensive experience in energy services business and project development and provides consulting in all phases of planning, start-up and operation of energy services companies. Previously, as vice president and general manager of International Energy Services Company (INTESCO), he was responsible for the management of all financial, engineering and project management resources required to implement energy efficiency and alternative energy projects on an international basis. In that capacity, he established energy services subsidiaries and joint ventures in Australia, India and the Czech Republic. Earlier in his career, as cofounder and president of Energy Resource Associates, he was instrumental in bringing Johnson Controls into the energy services business and positioning them as a leader in the industry. Previously, for American Building Maintenance Industries (ABMI), he helped launch Amtech Energy Services, the first energy services subsidiary of a fortune 500 firm. He holds an MBA in Finance from Boston University's Graduate School of Management (1987), and a BA in Environmental Studies with emphasis in energy issues from the University of California, Berkeley Campus (1976).

Jerry C. Comer - Mr. Comer is a senior principal of Energy Alliance Group with broad expertise in marketing, manufacturing, and operations. For the last 21 years he has helped technology-based companies develop new markets and businesses. Mr. Comer has worked with dozens of companies throughout the United States qualifying and developing new business opportunities. Recent projects include: development of a business and operating plan for Electricar Credit Corp; development of a business plan for a US Electricar/Hawaiian Electric Company joint venture; creation of a tactical market plan for US Electricar-Hawaii; development of a business plan for a joint venture between US Electricar and Niagara Mohawk; and development of a business plan for solar thermal hot water services for Wisconsin Public Service Corporation. Previously, as marketing manager for Texas Instruments, Mr. Comer created strategic and tactical market plans for two international business units and developed an evaluation system for new businesses. During his career he has managed manufacturing, quality assurance and purchasing operations in separate assignments at the vice president level. Experience in these areas include ISO-9000, Continuous Improvement, TQM and SPC. He holds an MBA from Northeastern University (1983), and a BS in Electrical Engineering from New Jersey Institute of Technology (1974).

\section{For more information, contact:}

\author{
Boston, Massachusetts: \\ Chester R. Lyons \\ Energy Alliance Group \\ 59 Dunster Road \\ Boston, MA 02130
}

Tel. (617) 522-4815

Fax (617) 522-5035

\author{
Boulder, Colorado: \\ Jerry C. Comer \\ Energy Alliance Group \\ 5255 Holmes Place \\ Boulder, CO 80303
}

Tel. (303) 786-7986

Fax (303) 473-9830 


\section{REPORT DOCUMENTATION PAGE}

Form Approved

OMB NO. 0704-0188

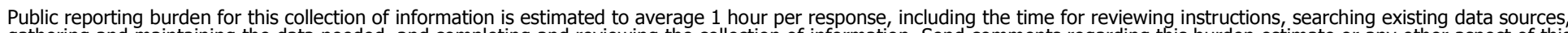

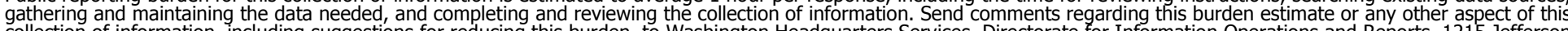

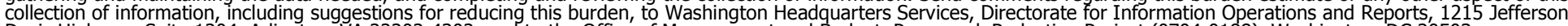

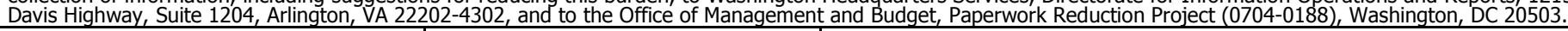

\begin{tabular}{|l|l|l|l|}
\hline 1. AGENCY USE ONLY (Leave blank) & $\begin{array}{l}\text { 2. REPORT DATE } \\
\text { June } 1999\end{array}$ & $\begin{array}{l}\text { 3. REPORT TYPE AND DATES COVERED } \\
\text { Subcontract Report }\end{array}$ \\
\hline 4. TITLE AND SUBTITLE &
\end{tabular}

Business Opportunity Prospectus for Utilities in Solar Water Heating

5. FUNDING NUMBERS

6. $A U T H O R(S)$

SH916001

Energy Alliance Group

7. PERFORMING ORGANIZATION NAME(S) AND ADDRESS(ES)

Energy Alliance Group

8. PERFORMING ORGANIZATION REPORT NUMBER

5255 Holmes Place

Boulder, CO 80303

EL 550-25976

9. SPONSORING/MONITORING AGENCY NAME(S) AND ADDRESS(ES)

National Renewable Energy Laboratory

10. SPONSORING/MONITORING AGENCY REPORT NUMBER

1617 Cole Blvd.

Golden, CO 80401-3393

EL-550-25976

\section{SUPPLEMENTARY NOTES}

NREL Technical Monitor:

12a. DISTRIBUTION/AVAILABILITY STATEMENT

National Technical Information Service

12b. DISTRIBUTION CODE

U.S. Department of Commerce

5285 Port Royal Road

Springfield, VA 22161

13. ABSTRACT (Maximum 200 words)

Faced with deregulation and increasingly aggressive competition, utilities are looking for new products and services to increase revenues, improve customer loyalty and retention, and establish barriers to market erosion. With open access now a reality, and retail wheeling just around the corner, business expansion via new products and services is now the central goal for most utilities in the United States. It may seem surprising that solar thermal energy as applied to heating domestic hot water - an idea that has been around for a long time - offers what utilities and their residential customers want most in a new product/service. This document not only explains how and why, it shows how to get into the business and succeed on a commercial scale.

14. SUBJECT TERMS

utilities, water heating, solar water heating, hot water, renewable energy, solar energy, deregulation, energy policy; environment; environment policy; utility restructuring

17. SECURITY CLASSIFICATION OF REPORT
18. SECURITY CLASSIFICATION OF THIS PAGE
19. SECURITY CLASSIFICATION OF ABSTRACT
15. NUMBER OF PAGES 98

16. PRICE CODE

20. LIMITATION OF ABSTRACT

Standard Form 298 (Rev. 2-89)

Prescribed by ANSI Std. Z39-18 